Article

\title{
Development of Nanofluids for Perdurability in Viscosity Reduction of Extra-Heavy Oils
}

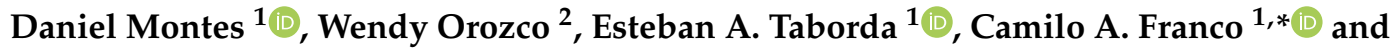 \\ Farid B. Cortés ${ }^{1, *}$ \\ 1 Grupo de Investigación en Fenómenos de Superficie-Michael Polanyi, Universidad Nacional de \\ Colombia-Sede Medellín, Medellin 050034, Colombia; damontespi@unal.edu.co (D.M.); \\ eatabord@unal.edu.co (E.A.T.) \\ 2 BCR Supply S.AS., Calle 7768 H 61, Bogotá 111061, Colombia; gteinvestigacion.bcr@gmail.com \\ * Correspondence: caafrancoar@unal.edu.co (C.A.F.); fbcortes@unal.edu.co (F.B.C.)
}

Received: 19 January 2019; Accepted: 13 March 2019; Published: 20 March 2019

\begin{abstract}
The primary objective of this study is the development of nanofluids based on different diluent/dispersant ratios (DDR) for extra-heavy oil (EHO) viscosity reduction and its perdurability over time. Different diluents such as xylene, diesel, $n$-pentane, and $n$-heptane were evaluated for the formulation of the carrier fluid. Instability of asphaltenes was assessed for all diluents through colloidal instability index (CII) and Oliensis tests. Rheology measurements and hysteresis loop tests were performed using a rotational rheometer at $30^{\circ} \mathrm{C}$. The $\mathrm{CII}$ values for the alkanes type diluents were around 0.57 , results that were corroborated with the Oliensis tests as asphaltenes precipitation was observed with the use of these diluents. This data was related to the viscosity reduction degree (VRD) reported for the different diluents. With the use of the alkanes, the VRD does not surpass the $60 \%$, while with the use of xylene a VRD of approximately $85 \%$ was achieved. Dimethylformamide was used as a dispersant of the nanoparticles and had a similar VRD than that for xylene (87\%). Subsequent experiments were performed varying the DDR (xylene/dimethylformamide) for different dosages up to $7 \mathrm{vol} \%$ determining that a DDR $=0.2$ and a dosage of $5 \mathrm{vol} \%$ was appropriated for enhancing EHO VRD, obtaining a final value of $89 \%$. Different $\mathrm{SiO}_{2}$ nanoparticles were evaluated in the viscosity reduction tests reporting the best results using $9 \mathrm{~nm}$ nanoparticles that were then included at $1000 \mathrm{mg} \cdot \mathrm{L}^{-1}$ in the carrier fluid, increasing the VRD up to $4 \%$ and enhancing the perdurability based on the rheological hysteresis and the viscosity measurements for 30 days. Results showed a viscosity increase of 20 and $80 \%$ for the crude oil with the nanofluid and the carrier fluid after 30 days, respectively. The nanoparticles have a synergistic effect in the viscosity reduction and the inhibition of the viscoelastic network re-organization (perdurability) after treatment application which was also observed in the rheological modeling carried out with Cross and Carreau models as the reported characteristic relaxation time was increased almost a 20\%. Moreover, the Vipulanandan rheological model denotes a higher maximum stress value reached by the EHO with the addition of nanofluids which is derived from the EHO internal structure rearrangement caused by the asphaltenes adsorption phenomenon.
\end{abstract}

Keywords: diluents; dispersant; nanofluids; perdurability; rheological hysteresis; viscosity reduction degree

\section{Introduction}

With the increasing energy demand around the globe, conventional sources of energy have been used for its supply with a substantial decrease in the reserves [1]. In this context, several investigations have been carried out, showing the importance of extra heavy oils (EHO) and analogous, due to their 
vast reserves worldwide [2,3]. Nevertheless, the physicochemical properties of EHO such as low API gravity and high contents of heavy components such as resins and asphaltenes lead to high viscosities through the formation of a complex viscoelastic network [4] and generate substantial technological challenges for production, transporting and refining operations [5-7]. The crude oil heavy fractions, particularly the asphaltenes, are high dipole moment compounds [8] due to its chemical structure which is composed by a polyaromatic core surrounded by aliphatic chains and may contain heteroatoms such as oxygen, nitrogen, and sulfur $[9,10]$. The high polarity caused by this chemical structure generates in this compounds a self-association characteristic, leading to the asphaltene arrangement in aggregates that, depending on their sizes, can be classified as nanoaggregates or clusters [11]. In light crude oils, this aggregation can cause asphaltene precipitation and its posterior deposition [12]. However, in EHO the high amount of resins tends to stabilize these aggregates, leading to the configuration of the internal fluid structure in the aforementioned complex viscoelastic network which leads to ultra-high viscosities [6] that hinders the oil mobility in the reservoir and its transportation under surface conditions.

Commonly, for the transportation process of this type of crude oil [13] different techniques are used for viscosity reduction such as heating [14,15], and solvents, which could lead to non-cost-effective operations [16,17]. Solvents and/or light hydrocarbons are mixed with the EHO for reducing the viscosity to a proper condition for transportation according to the recent standards [13-19]. Among the employed diluents, kerosene and light oils showed unsatisfactory performance caused by asphaltenes destabilization, pressure drop increase due to flowing area reduction [20], and insufficient viscosity reduction [21]. Additional treatments include the use of organic solvents and subsequent mixtures with hydrocarbons, slightly improving the effectiveness in viscosity reduction and increasing the expenses of the process. Furthermore, naphtha has been proved to be an effective solvent with acceptable compatibility with asphaltenes [21,22], property which may be enhanced with the inclusion of different additives to the system. Although dilution by naphtha is the most common technique for EHO transportation in the oil and gas industry, this can be costly and could have a negative environmental impact due to the massive amounts of diluent employed and the low perdurability over time [18,23].

Nowadays, nanotechnology has acquired a preponderant role in the oil industry as a cost-effective emergent technology [24], in different applications due to the exceptional properties of nanoparticulated materials such as high dispersibility [25,26] and surface-area-to-volume ratios [27], as well as selectivity for adsorption of heavy fractions of EHO, particularly asphaltenes [12,28,29]. The asphaltenes adsorption over the nanoparticles generates the reduction of the aggregate size in the EHO matrix [30], which changes the microstructure aggregation by disruption of the viscoelastic network and further leads to the crude oil viscosity reduction [7,30-33]. Hence, several authors have studied the use of nanofluids for crude oil viscosity reduction. Alomair et al. [31], used a mixture of silicon, alumina, nickel oxide and titanium oxide nanoparticles with saline water as a carrier fluid for increasing oil mobility by an inverse emulsion formation, which foments viscosity reduction. Recent studies have included the impact of nanoparticles of different chemical nature in various carrier fluids looking for the reduction of viscosity of heavy and extra-heavy oils [30,32,33]. It is worth to mention that the design of the carrier fluid is of primary importance as it should contain an oil-soluble phase or diluent, as well as a nanoparticles dispersant for stabilizing the nanofluid.

Further, through the studies above, viscosity reduction degrees (VRD) larger than $8 \%$ has been achieved, reducing the naphtha requirements for obtaining the transport conditions in the pipeline in almost $50 \mathrm{vol} \%$ regarding the system in the absence of nanoparticles [33,34]. However, satisfactory results have been achieved in the reduction of the viscosity of crude oil through nanotechnology-based materials. Taborda et al. [7] and Aristizabal-Fontal et al. [32], have developed related studies with this research subject. However, these works lack in a proper demonstration of these treatments capabilities as a function of time on the durability of the reduction of viscosity and thixotropic measurements, and the direct relationship with the organization of the viscoelastic network altered by the presence of nanoparticles. It is worth to mention that in the scientific literature there are no studies on this topic. 
Hence, the main objective of this work is to evaluate the viscosity reduction perdurability because of the EHO internal structure modification obtained through the designing of nanofluids based on the synergy between the carrier fluids and nanoparticles as a function of the diluent/dispersant ratios. This technology could result in an alternative technique to overcome the aforementioned issues during EHO transporting operations by considerably reducing economic expenses related to the use of additional of solvents.

\section{Materials and Methods}

\subsection{Materials}

Two commercial $\mathrm{SiO}_{2}$ nanoparticles and tetraethylorthosilicate (TEOS)-based in-house synthesized $\mathrm{SiO}_{2}$ nanoparticles were employed in this study. The commercial $\mathrm{SiO}_{2}$ nanoparticles were provided by Sigma-Aldrich (St. Louis, MO, USA) and BCR Supply S.A.S. (Bogotá, Colombia). The synthesized nanoparticles were obtained through the sol-gel method based on the reported by Stöber et al. [35], and described in previous works $[28,36]$. Briefly, a solution with tetraethylorthosilicate (TEOS) as the precursor of silicon, ethanol, and $\mathrm{NH}_{4} \mathrm{OH}$, is prepared and the mixture is manually stirred, in a process that continues for $1 \mathrm{~h}$ and finally dried at $80{ }^{\circ} \mathrm{C}$ for $24 \mathrm{~h}$ to remove any remaining water fraction. The nanoparticles were named as S9, S66, and S11, respectively, according to their mean particle size. Diesel provided by a local company, xylene (BCR Supply S.A.S., Bogotá, Colombia), n-pentane (Panreac AppliChem, Darmstadt, Germany), and $n$-heptane (Panreac AppliChem, Darmstadt, Germany), were used as the EHO diluents and evaluated in the viscosity reduction experiments. Dimethylformamide (BCR Supply S.A.S., Bogotá, Colombia) was employed as the nanoparticles dispersant. Toluene (Merck KGaA, Darmstadt, Germany) with a 99\% purity was used for performing Oliensis tests and for the obtention of the adsorption isotherms of $n-C_{7}$ asphaltenes over the selected nanoparticles. The $n-C_{7}$ asphaltenes were isolated from the crude oil by $n$-heptane following a standard procedure described in previous work [12,37]. A Colombian EHO with $6.4^{\circ}$ API and $34 \mathrm{mN} \cdot \mathrm{m}^{-1}$ of surface tension was used for carrying out the experiments. The employed crude oil was characterized by its saturates, aromatics, resins, and asphaltenes content through a micro-deasphalting technique with $n$-heptane coupled to thin-layer chromatography following the IP 469 standard using a TLC-FID/FPD Iatroscan MK6 (Iatron Labs Inc, Tokyo, Japan), encountering mass percentages of 13.02, 16.93, 49.86 and $20.19 \mathrm{wt} \%$, respectively.

\subsection{Methods}

\subsubsection{Nanoparticles/Nanofluid Characterization}

The employed nanoparticles were characterized by their physicochemical properties such as surface area $\left(\mathrm{S}_{\mathrm{BET}}\right)$, mean particle size $(\mathrm{dp} 50)$, isoelectric point $\left(\mathrm{pH}_{\mathrm{pzc}}\right)$, and surface functional groups. Hydrodynamic diameters of nanoparticles were estimated by the dynamic light scattering (DLS) technique using a NanoPlus-3 (Micromeritics, Atlanta, GA, USA). The surface area $\left(\mathrm{S}_{\mathrm{BET}}\right)$ was determined through the Brauneur-Emmett-Teller method [38] by $\mathrm{N}_{2}$ physisorption at $-196^{\circ} \mathrm{C}$ using a surface area analyzer Gemini VII 2390r (Micromeritics) [39]. The characterization of functional groups on the nanoparticles surface was performed by Fourier transformed infrared spectroscopy (FTIR) with an IRAffinity-1 FTIR (Shimadzu, Kyoto, Japan) spectrophotometer [40,41]. The $\mathrm{pH}_{\mathrm{pzc}}$ for each nanoparticle was obtained in an aqueous phase performing zeta potential measurements using the NanoPlus-3.

Through the evaluation of different diluent/dispersant ratios DDR, it was obtained a final formulation of the carrier fluid to be implemented alongside the chosen nanoparticles according to their performance in EHO viscosity reduction. The obtained carrier fluid and nanofluid were characterized by their density, viscosity using a Kinexus Pro+ (Malvern Instruments, Worcestershire, 
UK) rheometer and visual appearance. The EHO surface tension in the absence and presence of the nanofluid was also studied using a force tensiometer-K11 (Krüss, Hamburg, Germany).

\subsubsection{Asphaltenes Stability Tests}

The colloidal instability index (CII) [42] was calculated for EHO samples including the evaluated diluents to determine the effect of each diluent in the asphaltenes stability in the oil matrix. Furthermore, the obtained results were experimentally corroborated using the Oliensis technique [43,44]. The process consists of the preparation of EHO/Toluene mixtures in a 1:1 ratio. The mixture is stirred at $500 \mathrm{rpm}$ until homogeneity and left to stand for $2 \mathrm{~min}$. An aliquot is taken and placed in a filter paper. Then, $2 \mathrm{~mL}$ of the evaluated diluent is added to the solution and further stirred to repeat the process above until the formation of a halo, indicating the asphaltenes precipitation. The sample was analyzed by polarized light microscopy using a Motic BA310 (Motic, Stockholm, Sweden) microscope.

\subsubsection{Asphaltenes Adsorption Isotherms}

Adsorption isotherms of asphaltenes over the selected $\mathrm{SiO}_{2}$ nanoparticles were obtained for determining the role of the adsorption process in the viscosity reduction of crude oil. For the quantification of the amount of adsorbed asphaltenes, a calibration curve of absorbance vs. asphaltenes concentration in a toluene model solution shown in Figure S1 of the supplementary material was obtained using an UV-Vis Genesys 10 S spectrophotometer (Thermo Scientific, Waltham MA, USA) at a wavelength of $295 \mathrm{~nm}$. Solutions between 100 and $2000 \mathrm{mg} \cdot \mathrm{L}^{-1}$ of asphaltenes in toluene were prepared from a stock solution of $5000 \mathrm{mg} \cdot \mathrm{L}^{-1}$, and for a fixed nanoparticles concentration of $10 \mathrm{~g} \cdot \mathrm{L}^{-1}$ to promote their precipitation after asphaltenes adsorption to provide a better supernatant analysis. The amount of adsorbed asphaltenes was determined by mass balance according to the procedure described by Guzmán et al. [27]. Additionally, solid-liquid-equilibrium (SLE) model was used to describe the adsorption isotherms behavior [45].

\subsubsection{Viscosity and Rheological Behavior Measurements}

Viscosity $(\mu)$ and rheology measurements were performed with the rheometer equipped with a Peltier stage which provides refined temperature control, using a GAP of $0.3 \mathrm{~mm}$ with the parallel plate-plate geometry optimal for high viscous fluids. For the EHO-diluents mixtures, results were corroborated using a cone-plate geometry. Measurements were made at different shear rates ranging from 0 to $100 \mathrm{~s}^{-1}$ for the EHO with the evaluated diluents, nanoparticles and nanofluids, a range which was chosen as it represents significant stresses obtained during the EHO transportation initialization, which is the more critical condition for the transportation designing process and start-up. The viscosity reduction degree (VRD) was calculated according to Equation (1):

$$
V R D=\left(\frac{u_{r e f}-u_{\text {treat }}}{u_{\text {ref }}}\right) \times 100
$$

where, $\mu_{\text {ref }}$ and $\mu_{\text {treat }}$ are the reference viscosity and the viscosity after treatment, respectively [30,32].

The assessment of the different diluents was made through their VRD response at a constant shear rate of $10 \mathrm{~s}^{-1}$ for a fixed dosage of $5 \mathrm{vol} \%$. Dimethylformamide (DMF) was selected as the nanoparticles dispersant due to its chemical structure that may induce a disruption over the viscoelastic network of the EHO [46,47].

The DDR was evaluated for the best diluent according to the experiments above looking for an accurate design of the carrier fluid. For this evaluation, the viscosity was measured for each component and different DDR's between 0.1 and 0.9 at a fixed dosage of $5 \mathrm{vol} \%$ in the absence and presence of $1000 \mathrm{mg} \cdot \mathrm{L}^{-1}$ of the selected $\mathrm{SiO}_{2}$ nanoparticles. The nanoparticles were chosen according to its capacity for viscosity reduction, and the dosage was selected based on previous studies [7]. The dosage 
of the nanofluid was varied from 0.5 to $7 \mathrm{vol} \%$ for the resulting DDR with higher VRD. It is worth to mention that the carrier fluid is composed of the DDR in the absence of nanoparticles.

The thixotropic behavior of the EHO in the presence of the obtained nanofluid and the carrier fluid was evaluated by perdurability of the VRD through viscosity measurements for 10 days and by hysteresis loop tests. The hysteresis loop tests were performed for two shear rates ramps from 0 to $100 \mathrm{~s}^{-1}$ and subsequently from 100 to $0 \mathrm{~s}^{-1}$.

\section{Rheological Modelling}

Different models have been proposed to describe the EHO rheological behavior [48,49], such as Ostwald-de Waele, Herschel-Bulkley, and Cross [50]. The models employed in this study to describe the crude oil in the absence and presence of the evaluated nanofluids and its components were the Cross model and the Carreau model, and the accuracy were evaluated using the root-square-mean error (RMSE\%) [30]. The following equation describes the Cross model:

$$
\mu=\mu_{\infty, \dot{\gamma}}+\frac{\mu_{0, \dot{\gamma}}-\mu_{\infty, \dot{\gamma}}}{1+\left(\alpha_{c} \dot{\gamma}\right)^{m}}
$$

where, $\mu(\mathrm{cP})$ is the fluid viscosity, $\alpha_{c}(\mathrm{~s})$ is the characteristic relaxation time, $\dot{\gamma}\left(\mathrm{s}^{-1}\right)$ is the shear rate, $m$ is a constant related to the fluid trend for having a Newtonian behavior, and $\mu_{\infty, \dot{\gamma}}(\mathrm{cP})$ and $\mu_{0, \dot{\gamma}}(\mathrm{cP})$ are the viscosity at infinite shear rate and viscosity at zero shear rate, respectively.

The Carreau model is described by the following equation:

$$
\mu=\mu_{\infty, \dot{\gamma}}+\frac{\mu_{0, \dot{\gamma}}-\mu_{\infty, \dot{\gamma}}}{\left(1+\left(\lambda_{c} \dot{\gamma}\right)^{2}\right)^{N}}
$$

where, $\mu(\mathrm{cP})$ is viscosity, $\lambda_{c}(\mathrm{~s})$ characteristic relaxation time, $\dot{\gamma}\left(\mathrm{s}^{-1}\right)$ shear rate, $\mathrm{N}$ constant, $\mu_{\infty, \dot{\gamma}}(\mathrm{cP})$ viscosity at infinite shear rate and $\mu_{0, \dot{\gamma}}(\mathrm{cP})$ viscosity at zero shear rate.

Additionally, a new hyperbolic model (Vipulanandan model) has been developed recently for describing the rheological properties of modified cement, drilling fluids [51-53], and hydraulic fracturing fluids [54], which compared to the power law based models is also able to predict the rheological behavior of the evaluated fluid at certain experimental conditions, as well as to estimate the maximum stress reached by the tested fluid at relatively high shear rates values. Hence, it was decided to use the Vipulanandan model for describing the breakdown flow curves of the EHO-Carrier-fluid and EHO-Nanofluid systems obtained through the hysteresis loop tests, in order to acquire additional information concerning the distinct EHO rheological properties modification derived from the final formulated carrier fluid and nanofluid addition. The following equation describes the Vipulanandan model:

$$
\tau=\tau_{0}+\frac{\dot{\gamma}}{A+D * \dot{\gamma}}
$$

where $\dot{\gamma}\left(\mathrm{s}^{-1}\right)$ is the shear rate, $A(\mathrm{~Pa} \cdot \mathrm{s})^{-1}$ and $D(\mathrm{~Pa})^{-1}$ are model parameters and $\tau$ and $\tau_{0}$ are the shear stress and yield stress respectively. Furthermore, for estimating the maximum stress $\tau_{\max }$ the next relation is used [51]:

$$
\tau_{\max }=\frac{1}{D}+\tau_{0}
$$

\section{Results and Discussion}

The results are divided into four main sections, namely: (i) nanoparticles characterization, (ii) formulation and evaluation of the carrier fluid in the viscosity reduction, (iii) nanofluids formulation and assessment considering the nanoparticles-asphaltene interactions, and (iv) evaluation of the 
viscosity reduction perdurability, including hysteresis loop tests and viscosity measurements for 30 days.

\subsection{Nanoparticles/Nanofluid Characterization}

Table 1 shows the mean particle size $\left(\mathrm{dp}_{50}\right)$, surface area $\left(\mathrm{S}_{\mathrm{BET}}\right)$, and isoelectric point $\left(\mathrm{pH}_{\mathrm{pzc}}\right)$ of the commercial and the TEOS-based synthesized $\mathrm{SiO}_{2}$ nanoparticles. Commercial nanoparticles have mean particle sizes of 9 and $66 \mathrm{~nm}$. Meanwhile, the synthesized $\mathrm{SiO}_{2}$ nanoparticles have a mean particle size of $11 \mathrm{~nm}$. Further, the nanomaterials were named S9, S11, and S66 according to their respective particle size. As expected, the surface area of the nanoparticles is reduced as the mean particle size increases with values of 389,210 and $51 \mathrm{~m}^{2} \cdot \mathrm{g}^{-1}$, respectively. The $\mathrm{pH}_{\mathrm{pzc}}$ for the three nanoparticles was $2.2 \pm 0.5$, indicating that for working $\mathrm{pH}$ values $>3.0$, the nanoparticles will remain stable in the carrier fluid due to the increase of the repulsion forces [55].

Table 1. Nanoparticles mean particle size (dp50), surface area (SBET) and isoelectric point (pHpzc).

\begin{tabular}{cccc}
\hline Nanoparticles & $\mathbf{d p 5 0}(\mathbf{n m})$ & $\mathbf{S}_{\mathbf{B E T}}\left(\mathbf{m}^{\mathbf{2}} \cdot \mathbf{g}^{-\mathbf{1}}\right)$ & $\mathbf{p H}_{\mathbf{p z c}}$ \\
\hline $\mathrm{S} 9$ & 9 & 389 & 2.5 \\
$\mathrm{~S} 11$ & 11 & 210 & 2.8 \\
$\mathrm{~S} 66$ & 66 & 50 & 1.5 \\
\hline
\end{tabular}

Figure S2 of the Supplementary Material shows the FTIR spectra of S9, S11, and S66 nanoparticles. For the three materials, the spectra show characteristic $\mathrm{SiO}_{2}$ bands assigned to different vibrations in the structure. Silanol (Si-OH) groups are visible in the band located at $3780-2470 \mathrm{~cm}^{-1}$ along with $\mathrm{O}-\mathrm{H}$ bond overlapping corresponding to water molecules [53]. Moreover, a band centered at $1630 \mathrm{~cm}^{-1}$ could correspond to deformation vibrations of adsorbed water molecules, while the band between 1000 and $1300 \mathrm{~cm}^{-1}$ shows the Si-O covalent bond vibrations. Furthermore, siloxane (O-Si-O) symmetric vibrations appear at about $808 \mathrm{~cm}^{-1}$ with its bending mode located at $470 \mathrm{~cm}^{-1}$ [54]. All nanoparticles characterized by FTIR analysis showed a similar behavior between them. However, the transmittance intensity of each one is different due to their surface chemical nature [55].

The nanofluid and carrier fluid characterization were carried out accounting for their density, viscosity and surface tension towards their inclusion in the EHO. Results are reported in Table 2, where little differences are observed in the nanofluid density and viscosity compared to the carrier fluid. Furthermore, it can be seen that the EHO surface tension is reduced from $34 \mathrm{mN} \cdot \mathrm{m}^{-1}$ to $26 \mathrm{mN} \cdot \mathrm{m}^{-1}$ and $21 \mathrm{mN} \cdot \mathrm{m}^{-1}$ with the use of the carrier fluid and the nanofluid, respectively. This behavior is derived from the use of dimethylformamide (DMF) which acts as a tensoactive agent [46], and the use of the nanoparticles. Visual appearance for both fluids is shown in Figure S3 of the Supplementary Material, where a difference in opacity is observed as the carrier fluid has a lighter aspect due to the absence of nanoparticles.

Table 2. Density and viscosity of the carrier fluid and nanofluid at $25^{\circ} \mathrm{C}$. The surface tension after their inclusion in the EHO is also reported.

\begin{tabular}{cccc}
\hline Fluid & Density $\left(\mathbf{g} \cdot \mathbf{m L}^{-\mathbf{1}}\right)$ & Viscosity at $\mathbf{2 5}{ }^{\circ} \mathbf{C}(\mathbf{c P})$ & Surface Tension in EHO $\left(\mathbf{m N} \cdot \mathbf{m}^{-\mathbf{1}}\right)$ \\
\hline Carrier fluid & 0.9399 & 8.9 & 26 \\
Nanofluid & 0.9541 & 10.5 & 21 \\
\hline
\end{tabular}

\subsection{Diluents Evaluation for Carrier Fluid Formulation}

\subsubsection{Effect of Different Diluents on the Viscosity Reduction}

The viscosity reduction with xylene, diesel, $n$-pentane, and $n$-heptane diluents was evaluated by triplicated for a fixed dosage of $5 \mathrm{vol} \%$ at $30{ }^{\circ} \mathrm{C}$, and a constant shear rate of $10 \mathrm{~s}^{-1}$. The effect of 
the DMF (dispersant of the nanoparticles) was also evaluated under the same conditions of dosage and temperature as previous studies have reported that it may also work as viscosity reducer [47]. The CII estimated for the EHO, and the EHO-diluents mixtures at a $5 \mathrm{vol} \%$ are shown in Table 3, where it is visible that with the addition of alkanes like diluents such as Diesel, $n$-pentane, and $n$-heptane, the asphaltenes are slightly less stable in the oil matrix. However, as these values do not surpass 0.7 , it can be considered that with the use of these compounds at the evaluated concentration, there will be no asphaltenes precipitation. The Oliensis tests also indicated that there was no asphaltene precipitation when xylene and Diesel were added to the crude oil. In the presence of the normal alkanes, asphaltene precipitation was observed after addition of 50 and $75 \mathrm{vol} \%$ of $n$-pentane and $n$-heptane, respectively. Furthermore, the Oliensis results indicate that under the conditions of evaluation of dosages $\leq 5 \mathrm{vol} \%$, asphaltene precipitation would not occur. Hence, we can conclude that the viscosity reduction is due to the phenomena of the interaction of the nanofluids and crude oil.

Table 3. Colloidal instability index (CII) determined for the extra-heavy oil (EHO), and its mixtures with different diluents at a fixed dosage of $5 \mathrm{vol} \%$.

\begin{tabular}{cc}
\hline \multicolumn{2}{c}{ Colloidal Instability Index } \\
\hline EHO & 0.5 \\
EHO-Pentane & 0.57 \\
EHO-Heptane & 0.57 \\
EHO-Diesel & 0.57 \\
EHO-Xylene & 0.46 \\
\hline
\end{tabular}

Figure 1 shows the effect of the evaluated diluents in the viscosity reduction degree (VRD) at $30{ }^{\circ} \mathrm{C}$ for a fixed diluent dosage of $5 \mathrm{vol} \%$. It can be observed that the DMF addition showed a VRD of $87 \%$. For this reason, it will be selected as a dispersant for the preparation of the nanofluid. This VRD can be explained by the resonance of the carbonyl group [56] that leads to a high dipole moment and promotes an amphoteric behavior for this compound, property that provides the ability to interact with asphaltenes aggregates rather than with the crude oil lighter components, affecting the EHO internal structure. This behavior which is prompted by the DMF high dipole moment has been demonstrated in previous works, in which it has been exposed to the enhanced interaction between asphaltenes and polar organic compounds $[17,22]$.

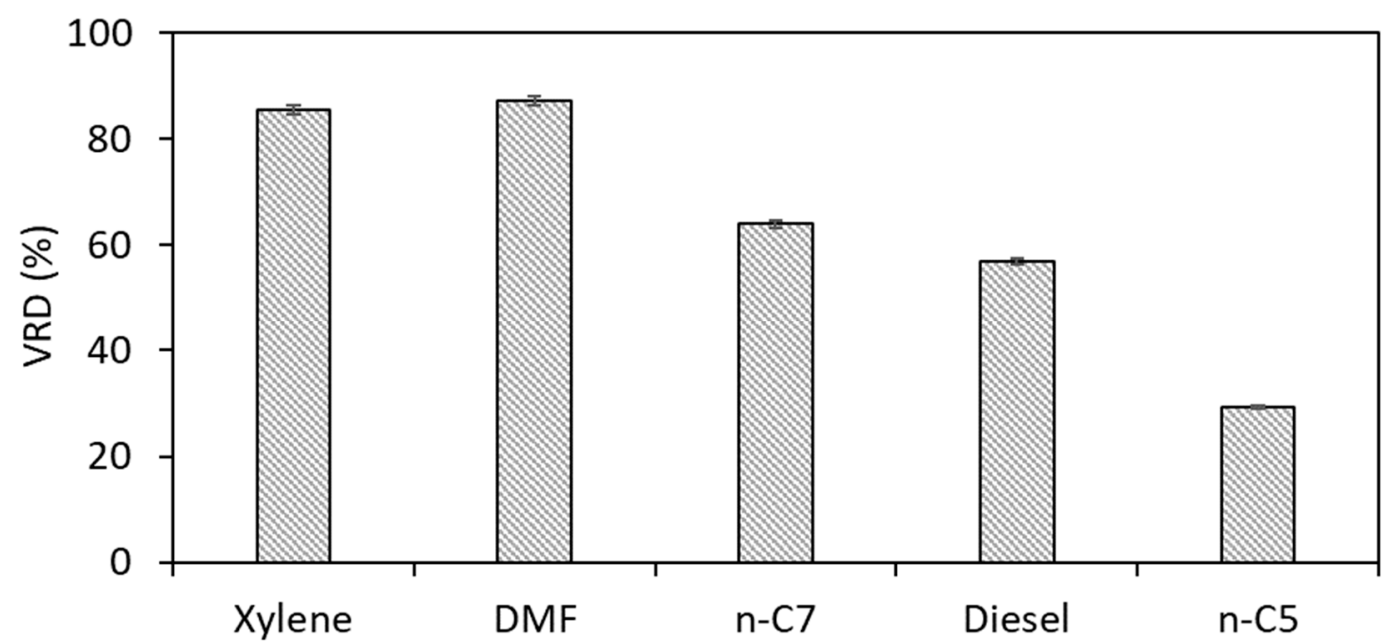

Figure 1. Effect of xylene, dimethylformamide (DMF), $n$-heptane $\left(n-C_{7}\right)$, diesel, and n-pentane $\left(n-C_{5}\right)$ in the viscosity reduction degree (VRD) of an extra-heavy oil at $30{ }^{\circ} \mathrm{C}$ for a fixed diluent dosage of $5 \mathrm{vol} \%$ at a fixed shear rate of $10 \mathrm{~s}^{-1}$. 
For the other fluids used in this work, the highest VRD was obtained with xylene with a value of the $85 \%$, while the performance achieved with the other solvents was lower than $65 \%$. These results can be explained by the solvent quality regarding oil dilution which may induce a reconfiguration in the internal fluid structure due to the asphaltenes clusters dispersion [56]. It is also observed that the lowest VRD was obtained with $n$-pentane and could be associated with the formation of large asphaltenes clusters. The viscosity measurements were corroborated using plate-plate and cone-plate geometries to avoid errors related to the used geometry, results can be found for xylene in Figure S4 of the supplementary material text. The obtained results showed that the errors between both tests are lower than $3 \%$, demonstrating the geometry adjustment to the conditions of the experiments.

\subsubsection{DDR Evaluation}

According to the results in Section 4.2.1, different xylene and DMF (X/DMF) ratios were evaluated to determine the influence of both compounds in the EHO viscosity reduction. The experiments were carried out by triplicate at $30^{\circ} \mathrm{C}$ and for a fixed dosage of $5 \mathrm{vol} \%$. Figure 2 shows the effect of the DMF ratio in the VRD of an extra-heavy oil at $30^{\circ} \mathrm{C}$ for a fixed diluent dosage of $5 \mathrm{vol} \%$ at a fixed shear rate of $10 \mathrm{~s}^{-1}$. It can be seen from Figure 2 that the highest viscosity reduction degree was obtained using a $5 \mathrm{vol} \%$ with an $\mathrm{X} / \mathrm{DMF}=0.2$. From these results, a synergy is observed between the dilution effect provided by xylene addition, and viscoelastic network disruption caused by the DMF presence, as both viscosity reduction mechanisms, are improved for $\mathrm{X} / \mathrm{DMF}<0.31$. Results are in accordance with previous studies, in which a viscosity reduction yielding a $92 \%$ was obtained using only the carrier fluid [30]. The mechanism of viscosity reduction of the carrier fluid could be dominated firstly by the viscoelastic network disruption obtained by the addition of DMF to the EHO, which is explained by its high dipole moment fomenting the interaction with the asphaltenes $[17,22]$, and secondly, by the dilution effect provided by the xylene presence in its formulation.

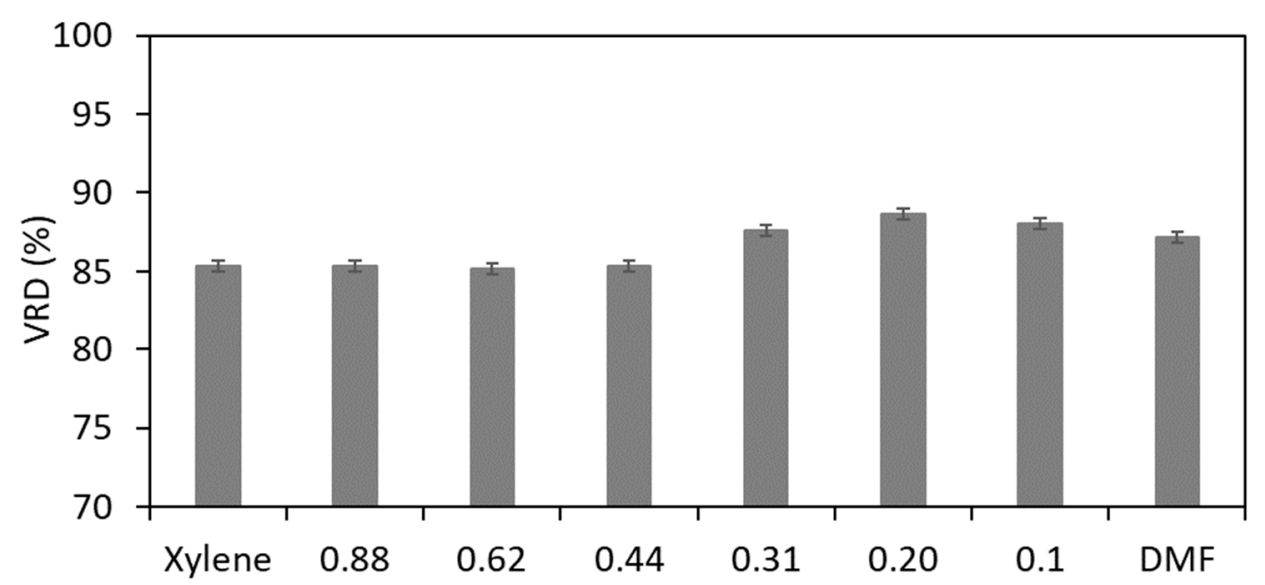

Figure 2. Effect of xylene/dimethylformamide (DMF) ratio in the viscosity reduction degree (VRD) of an extra-heavy oil at $30^{\circ} \mathrm{C}$ for a fixed diluent dosage of $5 \mathrm{vol} \%$ at a fixed shear rate of $10 \mathrm{~s}^{-1}$.

Hence, the dosage was varied from 0.5 to $7 \mathrm{vol} \%$ for a DDR $=0.2$. Figure 3 shows the effect of the carrier fluid dosage in the VRD of an extra-heavy oil at $30^{\circ} \mathrm{C}$ for $\mathrm{X} / \mathrm{DMF}=0.2$ at a fixed shear rate of $10 \mathrm{~s}^{-1}$. It can be observed from Figure 3 that as the carrier fluid concentration in crude oil is increased, the slope of viscosity reduction is lower. The higher slope in the VRD curve at low concentrations is presumably derived from the viscoelastic network disruption that has a positive effect on the EHO internal structure and further viscosity reduction. Meanwhile, for carrier fluid dosages $>5$ vol \%, the DMF may have no significant effect on the viscoelastic network disruption. Thus, it was concluded that a concentration of $5 \mathrm{vol} \%$ of the evaluated carrier fluid is enough for having a suitable performance in viscosity reduction. The standard deviation between the viscosity 
values obtained after the rheological measurements was negligible with an error $<2 \%$, confirming the reproducibility of the experiments.

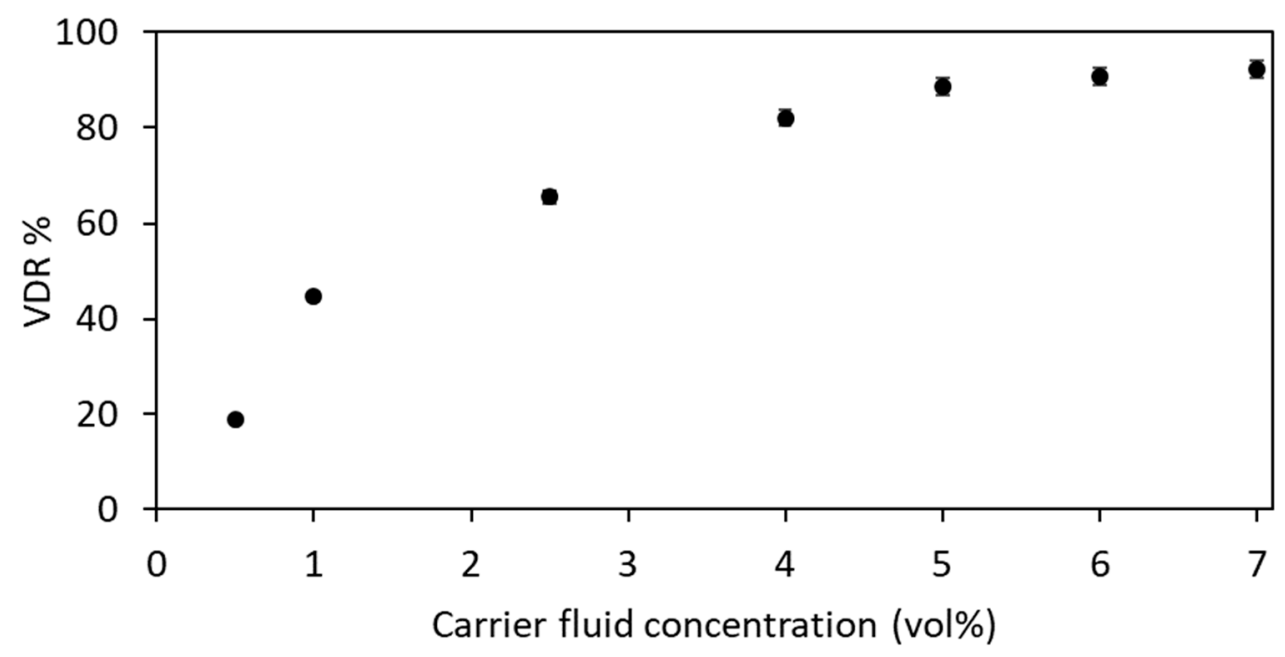

Figure 3. Effect of the carrier fluid dosage in the viscosity reduction degree (VRD) of an extra-heavy oil at $30{ }^{\circ} \mathrm{C}$ for a fixed xylene/dimethylformamide ratio of 0.2 at a fixed shear rate of $10 \mathrm{~s}^{-1}$.

\subsection{Nanofluids Formulation}

$\mathrm{SiO}_{2}$ nanoparticles have been used for the nanofluids formulation due to their high asphaltenes selectivity that foments the adsorption of these crude oil heavy fractions onto their surface $[12,28]$, leading to a reduction in the asphaltenes aggregates sizes in solution. This phenomenon is narrowly related to the $\mathrm{EHO}$ viscosity reduction [30] due to an internal structure modification derived by the complex viscoelastic network disruption [7,57]. In this sense, nanoparticles-asphaltenes interactions were studied through adsorption isotherms and rheological behavior tests before evaluating the nanofluid design and further effects on EHO, VRD and viscosity reduction perdurability.

\subsubsection{Asphaltenes Adsorption}

It has been proven that $\mathrm{SiO}_{2}$ nanoparticles have high selectivity for asphaltene adsorption, which is the primary cause of the viscoelastic network modification that leads to viscosity reduction in $\mathrm{HO}$ and $\mathrm{EHO}[7,12,30,57]$. The influence of nanoparticles addition in $\mathrm{HO}$ and $\mathrm{EHO}$ rheological behavior has been determined by evaluating the adsorption phenomenon of crude oil heavy compounds such as asphaltenes. The nanoparticle with higher asphaltene uptake will be selected for the final formulation of the nanofluid. The adsorption isotherms of asphaltenes at $30{ }^{\circ} \mathrm{C}$ are shown in Figure S5 of the Supplementary Material together with the SLE model fitting. Also, Table S1 of the Supplementary Material summarizes the obtained SLE model parameters. The obtained adsorption isotherms follow a Type I behavior according to the International Union of Pure and Applied Chemistry (IUPAC) classification [58]. The highest asphaltene adsorption was achieved with the S9 nanoparticles that have the lowest mean particle size and highest value of the surface area. Also, from the results in Table S1, it can be seen that the highest affinity (lower value of the $H$ parameter) is obtained with the S9 nanoparticles. Thus, based on the previous results [30], it is expected to achieve a better VRD using the $S 9$ nanoparticles.

\subsubsection{Nanoparticles-Asphaltenes Interaction Effect in the Viscosity Reduction}

The viscosity reduction due to nanoparticles addition was evaluated at a concentration of $1000 \mathrm{mg} \cdot \mathrm{L}^{-1}$ in the EHO according to previous findings [7]. Figure 4 shows the rheological behavior together with the Cross model for the EHO in the absence and presence of S9, S11 and S66 nanoparticles at a fixed temperature of $30^{\circ} \mathrm{C}$ with a dosage of $1000 \mathrm{mg} \cdot \mathrm{L}^{-1}$. It can be seen that the viscosity decreases 
as the shear rate increases for the crude oil in the absence and presence of the nanoparticles, indicating a pseudoplastic nature [59]. The VRD decreased in the order S9 $>$ S11 > S66 in the whole range of shear rate evaluated. These results are intimately related to nanoparticles adsorptive capacity and its ability to reduce the asphaltene aggregates size, leading to the reconfiguration of the oil matrix structure. Taborda et al. [34] evaluated the effect of nanoparticles inclusion on light crude oil, a de-asphalted oil (DAO), a reconstituted crude oil, and heavy oil. The authors report that the effect of nanoparticles in viscosity is the viscoelastic network disruption for crude oils with high asphaltene content (heavy oil and reconstituted crude oil). Nevertheless, for crude oils with low asphaltene content (light oil and DAO), the nanoparticles increase the viscosity of the system in agreement with Einstein's theory of hydrodynamic viscosity.

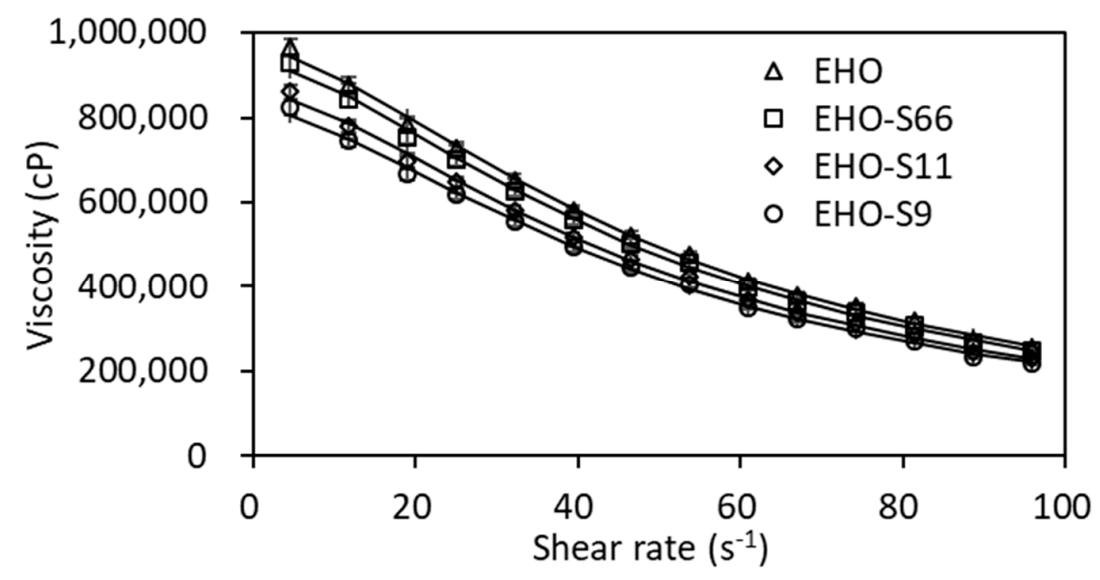

Figure 4. Rheological behavior of an extra-heavy oil (EHO) in the absence and presence of $1000 \mathrm{mg} \cdot \mathrm{L}^{-1}$ of $\mathrm{SiO}_{2}$ nanoparticles with different mean particle sizes of 9 (S9), 11 (S11), and $66 \mathrm{~nm}$ (S66) at $30{ }^{\circ} \mathrm{C}$. The symbols are experimental data, and the continuous lines are from the Cross model.

Table 4 shows the results of the Cross and Carreau model parameters for the rheological behavior of the EHO in the absence and presence of S9, S11 and S66 nanoparticles at a fixed temperature of $30{ }^{\circ} \mathrm{C}$ with a dosage of $1000 \mathrm{mg} \cdot \mathrm{L}^{-1}$. It can be observed a proper fitting of both models to the obtained experimental data, as the RSME values reported for those are much than $1 \%$. Additionally, the parameters of viscosity at zero and infinite shear rate are well adjusted for both models. It is observed that the fluid with the highest viscosity (EHO) has the highest values reported for the parameters and that the $\mathrm{EHO}$ in the presence of $1000 \mathrm{mg} \cdot \mathrm{L}^{-1}$ of $\mathrm{S} 9$ nanoparticles has the lower values despite the similarity in the characteristic relaxation time $\alpha_{c}$ and $\lambda_{c}$ between the evaluated samples. More information about Carreau Model fitting can be found in Figure S6 of the supplementary material.

Table 4. Cross and Carreau rheological models parameters for an extra-heavy oil (EHO) in the absence and presence of $1000 \mathrm{mg} \cdot \mathrm{L}^{-1}$ of $\mathrm{SiO}_{2}$ nanoparticles with different mean particle sizes of 9 (S9), 11 (S11), and $66 \mathrm{~nm}(\mathrm{~S} 66)$ at $30^{\circ} \mathrm{C}$.

\begin{tabular}{cccccc}
\hline Model & Parameters & EHO & EHO-S9 & EHO-S11 & EHO-S66 \\
\hline \multirow{5}{*}{ Cross } & $\mu_{0, \dot{\gamma}} \times 10^{3}(\mathrm{cP})$ & 982 & 829 & 870 & 932 \\
& $\mu_{\infty, \dot{\gamma}} \times 10^{3}(\mathrm{cP})$ & 125 & 108 & 115 & 120 \\
& $\alpha_{c}(\mathrm{~s})$ & 0.022 & 0.0223 & 0.0221 & 0.022 \\
& $m$ & 2.04 & 2.1 & 2.06 & 2.04 \\
& $\mathrm{RMSE} \%$ & 0.29 & 0.34 & 0.22 & 0.17 \\
& $\mu_{0, \dot{\gamma}} \times 10^{3}(\mathrm{cP})$ & 1011 & 832 & 862 & 933 \\
& $\mu_{\infty, \dot{\gamma}} \times 10^{3}(\mathrm{cP})$ & 134,893 & 84,385 & 102,000 & 105,000 \\
& $\lambda_{c}(\mathrm{~s})$ & 0.026 & 0.026 & 0.024 & 0.024 \\
& $N$ & 0.930 & 0.847 & 0.934 & 0.907 \\
& $\mathrm{RMSE} \%$ & 0.027 & 0.015 & 0.015 & 0.014 \\
\hline
\end{tabular}


Accordingly, the S9 nanoparticles were selected for the nanofluid formulation using the xylene/DMF mixture as the carrier fluid.

\subsubsection{Effect of Nanofluid in the Viscosity Reduction}

For the nanofluid formulation, the VRD was evaluated for different $\mathrm{X} / \mathrm{DMF}$ ratios with a given amount of S9 nanoparticles to accomplish a final dosage of $1000 \mathrm{mg} \cdot \mathrm{L}^{-1}$ (value is taken from Taborda et al. [34]) regarding the EHO. For guaranteeing an appropriate suspension, the nanofluid was stirred at $500 \mathrm{rpm}$ for $30 \mathrm{~min}$ and further sonicated. It is worth to mention that the inclusion of DMF as nanoparticles dispersant also provides suitable conditions for nanofluid stability.

Figure 5 shows the effect of the X/DMF ratio in the VRD at $30{ }^{\circ} \mathrm{C}$ for nanofluids at a fixed dosage of $5 \mathrm{vol} \%$ with $1000 \mathrm{mg} \cdot \mathrm{L}^{-1}$ of S9 nanoparticles and a fixed value of the shear rate of $10 \mathrm{~s}^{-1}$. From Figure 5 it can be seen that the highest VRD is obtained for $X / D F M=0.2$, which is in agreement with the results obtained for the evaluation of the carrier fluid. A slight increase in the viscosity reduction degree up to $4 \%$ is observed for the nanofluids in comparison with the carrier fluid of the xylene when the nanoparticles were added. The effect of nanoparticles in the viscoelastic network disruption is slight high due to the synergistic effect between DMF and S9 nanoparticles with the crude oil heavy fractions. Results are in agreement with previous studies, where a similar VRD was obtained with nanoparticles of the same chemical nature [30].

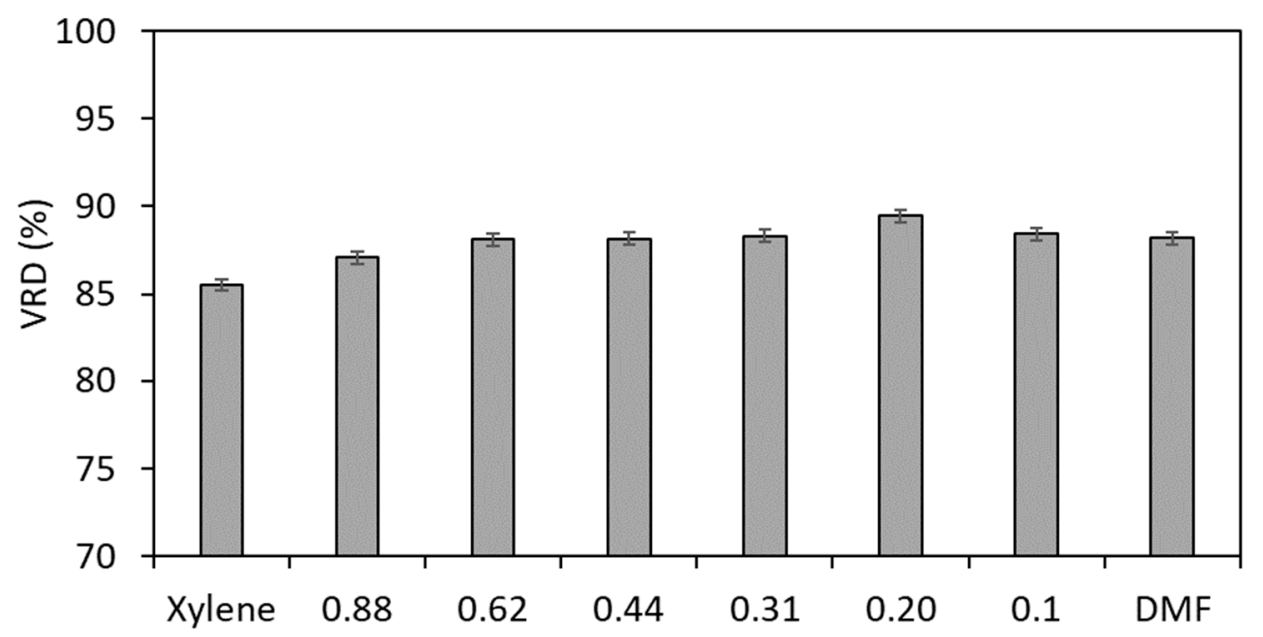

Figure 5. Effect of xylene/dimethylformamide (DMF) ratio in the viscosity reduction degree (VRD) of an extra-heavy oil (EHO) at $30{ }^{\circ} \mathrm{C}$ for a fixed nanofluid dosage of $5 \mathrm{vol} \%$ at a fixed shear rate of $10 \mathrm{~s}^{-1}$. S9 nanoparticles were dispersed in the carrier fluid to accomplish a concentration of $1000 \mathrm{mg} \cdot \mathrm{L}^{-1}$ regarding the $\mathrm{EHO}$.

The effect of the nanofluid dosage in the (VRD) at $30^{\circ} \mathrm{C}$ was evaluated at a fixed shear rate of $10 \mathrm{~s}^{-1}$, using a nanofluid composed of a carrier fluid with an X/DMF $=0.2$ and S9 nanoparticles at $1000 \mathrm{mg} \cdot \mathrm{L}^{-1}$ regarding the EHO as shown in Figure 6. At low dosages, the slope of the VRD curve is slightly higher for the nanofluid in comparison with the carrier fluid (Figure 3) and could be due to the enhanced effect of the nanoparticles and the synergistic effect with the DMF in the disruption of the viscoelastic network of the EHO. At high concentrations, the slope tends to decrease, which could be due to the dilution effect of the xylene at dosages higher than $4 \mathrm{vol} \%$ may be the primary viscosity reduction mechanism rather than the viscoelastic network disruption using nanoparticles addition [20,21]. It was also concluded that for both cases, the application of the carrier fluid and the nanofluid, a dosage of $5 \mathrm{vol} \%$ is sufficient for reducing the crude oil viscosity. Comparing the results in VRD obtained by the inclusion of the carrier fluid with those of the nanofluid, farther than the similar behavior in the dosage effect, there are slight effects in $\mathrm{EHO}$ viscosity reduction upon nanoparticles addition to the system. 


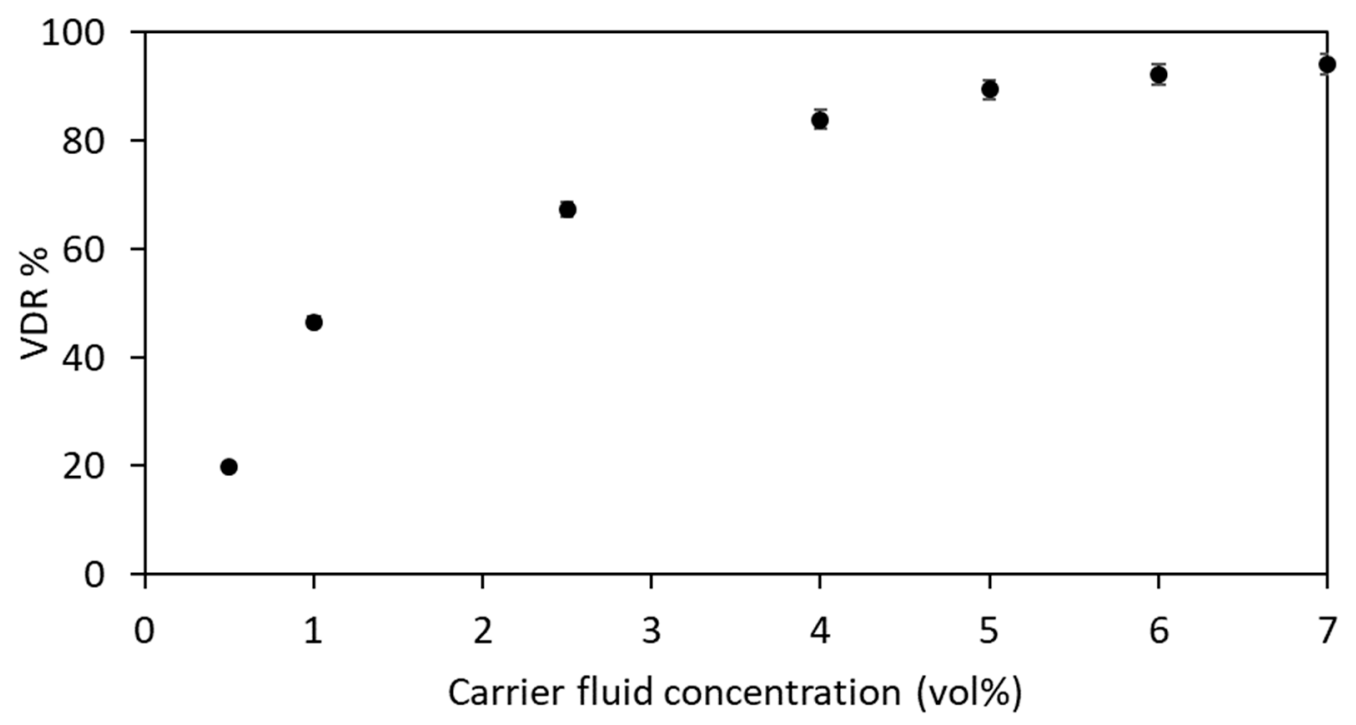

Figure 6. Effect of the nanofluid dosage in the viscosity reduction degree (VRD) of an extra-heavy oil (EHO) at $30{ }^{\circ} \mathrm{C}$ at a fixed shear rate of $10 \mathrm{~s}^{-1}$. The nanofluid is composed of a carrier fluid with a xylene/dimethylformamide ratio of 0.2 and S9 nanoparticles at $1000 \mathrm{mg} \cdot \mathrm{L}^{-1}$ regarding the EHO.

Nonetheless, nanoparticles may have an additional impact on crude oil internal structure, explained by their interaction with asphaltenes which could affect the thixotropic behavior of these fluids [7]. In several studies, it has been demonstrated that the crude oils, particularly the crude oils of low API gravity, have a thixotropic behavior which foments their ability of building-up their internal structure after a specific relaxation time when a stress is applied [60]. This strain susceptibility in crude oils is related to their internal structure stability and viscosity perdurability, which could be improved by the nanoparticles presence changing the EHO thixotropy by its internal structure modification [7]. Hence, it is of interest the study of the viscosity reduction perdurability upon the carrier fluid and nanofluid addition in the EHO, which may influence the build-up response of the crude oil internal structure.

\subsection{Perdurability Tests}

Two additional rheological tests were performed to evaluate the durability of the nanofluid and its ability to reduce viscosity over time, measurements of the VRD were performed for 30 days after treatments application, and a hysteresis loop of the crude oil in the presence and absence of the nanofluid was carried out.

\subsubsection{Hysteresis Loop Tests}

Hysteresis loop tests were carried out to evaluate the viscosity reduction durability over time after the addition of the carrier fluid and nanofluid. According to Mortazavi-Manesh and Shaw [60], the hysteresis flow curves demonstrates thixotropic behavior in the evaluated fluids, which is related with its internal structure breakage and build-up loop and further stability or susceptibility to stress changes.

The hysteresis tests were carried out alongside with viscosity changes as a function of time for an EHO treated with a $5 \mathrm{vol} \%$ of the nanofluid composed of an X/DMF $=0.2$ as carrier fluid and $1000 \mathrm{mg} \cdot \mathrm{L}^{-1} \mathrm{~S} 9$ nanoparticles. Commonly, certain types of fluids have rheological properties dependent on time. This is known as thixotropy or anti-thixotropy (or negative thixotropy), the most common case is thixotropy [61]. Figure 7 shows hysteresis behavior at $30^{\circ} \mathrm{C}$ for an $\mathrm{EHO}$ in the presence of $5 \mathrm{vol} \%$ of (a) the carrier fluid and (b) the nanofluid, together with the Cross model fitting. As the shear rate increases, the fluid shows a decrease in its viscosity exposing a shear thinning pseudoplastic 
behavior, which can be explained due to the structure breakdown (shear rate increasing) and recovery (shear rate decreasing) paths are different [61].

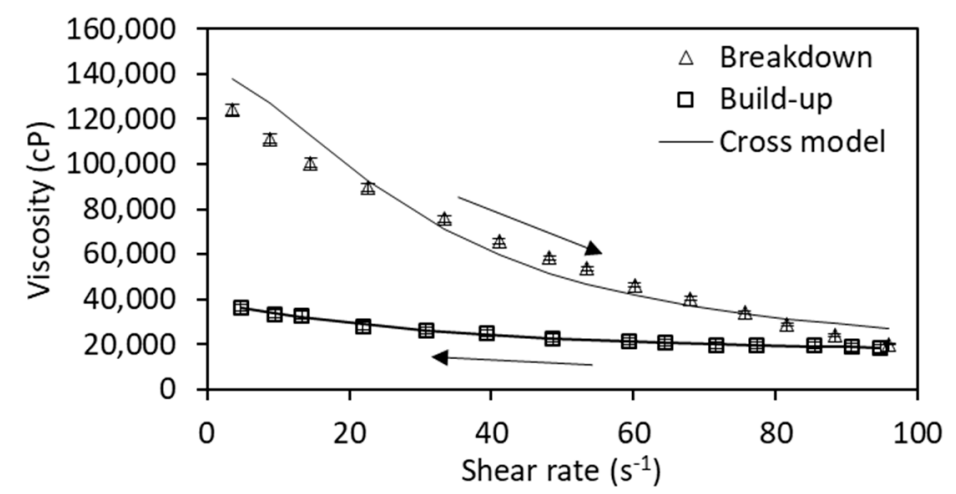

(a)

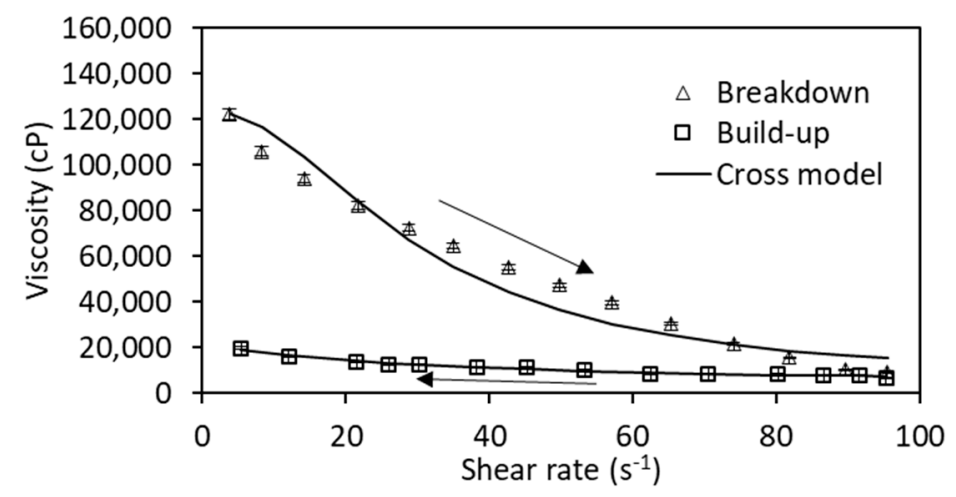

(b)

Figure 7. Hysteresis behavior at $30{ }^{\circ} \mathrm{C}$ for an extra-heavy oil in the presence of $5 \mathrm{vol} \%$ of (a) the carrier fluid composed of a xylene/dimethylformamide ratio of 0.2 , and (b) the nanofluid with S9 nanoparticles at $1000 \mathrm{mg} \cdot \mathrm{L}^{-1}$ composed by the carrier fluid. The symbols are experimental data, and the continuous lines are from the Cross model.

Also, from Figure 7 it can be clearly seen a less pronounced hysteresis for carrier fluid in comparison with the nanofluid, suggesting that the time needed for the recovery of the internal structure after stress submission is higher for the nanofluid and could be narrowly related to the stability of the internal fluid structure and viscosity sustainability in time. These results are in agreement with the phenomenological explanation presented by several researchers who studied the flow of thixotropic fluids [61-64]. Further, it can be said that the EHO viscosity after nanofluid inclusion is less time-dependent than the system with the carrier fluid.

Figure 8 shows the shear stress curves from the breakdown flow curves of the hysteresis loop tests carried out at $30{ }^{\circ} \mathrm{C}$ for (a) the EHO-Carrier fluid and (b) EHO-Nanofluid systems together with the Vipulanandan model fitting which was evaluated to obtain additional information on the different effects in the EHO rheological properties produced by the carrier fluid and nanofluid usage. As the hysteresis loop experiments require using the same sample for assessing the breakdown and build-up flow curves, it can be assumed that some rheological properties such as the maximum shear stress reached by the evaluated sample are the same regardless of the shear rate ramp. From Figure 8, the expected pseudoplastic behavior is observed for both cases in which the shear stress increases whit the shear rate increments. Lower values are obtained for the system including $\mathrm{SiO}_{2}$ nanoparticles, 
which is derived from the EHO additional internal structure modification due to the asphaltenes adsorption over nanoparticles surface [7].

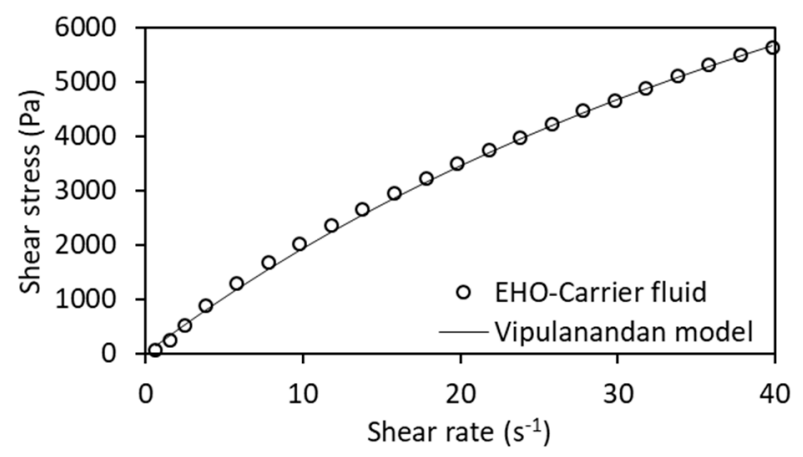

(a)

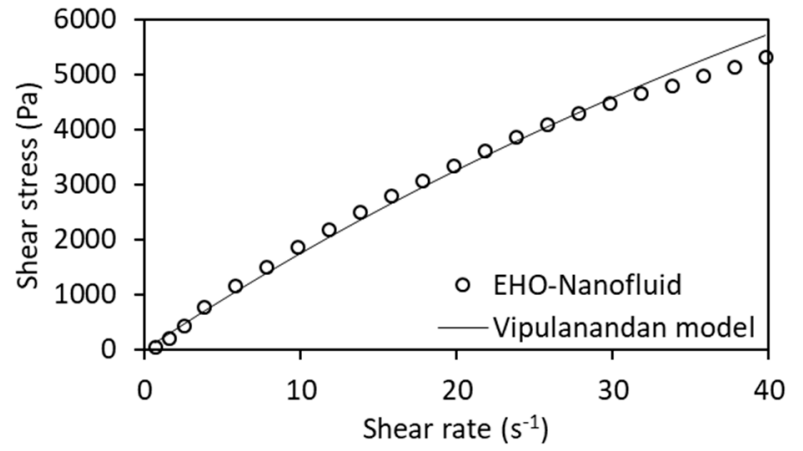

(b)

Figure 8. Shear stress curve from the breakdown flow curves of the hysteresis loop tests at $30{ }^{\circ} \mathrm{C}$ for an extra-heavy oil (EHO) in the presence of $5 \mathrm{vol} \%$ of (a) the carrier fluid composed of a xylene/dimethylformamide ratio of 0.2 , and (b) the nanofluid with S9 nanoparticles at $1000 \mathrm{mg} \cdot \mathrm{L}^{-1}$ composed by the carrier fluid. The symbols are experimental data, and the continuous lines are from the Vipulanandan model.

Table 5. Cross, Carreau and Vipulanandan models parameters for the hysteresis behavior at $30^{\circ} \mathrm{C}$ of extra-heavy oil in the presence of $5 \mathrm{vol} \%$ of the carrier fluid composed of a xylene/dimethylformamide ratio of 0.2 and the nanofluid with $\mathrm{S} 9$ nanoparticles at $1000 \mathrm{mg} \cdot \mathrm{L}^{-1}$ suspended in the carrier fluid.

\begin{tabular}{cccccc}
\hline \multirow{2}{*}{ Model } & \multirow{2}{*}{ Parameter } & \multicolumn{2}{c}{ Carrier Fluid } & \multicolumn{2}{c}{ Nanofluid } \\
\cline { 3 - 6 } & & Breakdown & Build-Up & Breakdown & Build-Up \\
\hline \multirow{5}{*}{ Cross } & $\mu_{0, \dot{\gamma}} \times 10^{3}(\mathrm{cP})$ & 141 & 37 & 124 & 12 \\
& $\mu_{\infty, \dot{\gamma}} \times 10^{3}(\mathrm{cP})$ & 49 & 11 & 21 & 3 \\
& $\alpha_{c}(\mathrm{~s})$ & 0.0331 & 0.0308 & 0.0332 & 0.0324 \\
& $m$ & 1.744 & 1.381 & 2.048 & 1.168 \\
& $\mathrm{RMSE} \%$ & 0.76 & 0.13 & 2.42 & 0.15 \\
\hline \multirow{5}{*}{ Carreau } & $\mu_{0, \dot{\gamma}} \times 10^{3}(\mathrm{cP})$ & 136 & 38 & 126 & 22 \\
& $\mu_{\infty, \dot{\gamma} \times 10^{3}(\mathrm{cP})}$ & 17,378 & 15,000 & 6819 & 6384 \\
& $\lambda_{c}(\mathrm{~s})$ & 0.0203 & 0.058 & 0.0235 & 0.0709 \\
& $N$ & 1.795 & 0.524 & 1.774 & 0.611 \\
& $\mathrm{RMSE} \%$ & 0.693 & 0.03 & 3.787 & 0.279 \\
\hline \multirow{5}{*}{ Vipulanandan } & $A(\mathrm{~Pa} . \mathrm{s})^{-1}$ & 0.004542 & - & 0.005282 & - \\
& $D(\mathrm{~Pa})^{-1}$ & 0.000063 & - & 0.000043 & - \\
& $\tau_{\max }(\mathrm{Pa})$ & 15,977 & - & 23,449 & - \\
& $\mathrm{RSME} \%$ & 1.53 & - & 1.92 & - \\
\hline
\end{tabular}


The estimated parameters of the Cross and Carreau models for the breakdown and build-up curves for both systems are shown in Table 5. The parameters related to the viscosity in the limit situations $\mu_{0}$, and $\mu_{\infty}$, are consistent with the experimental results, it can be noted how the estimated viscosity at an infinite shear rate is lower for the nanofluid than for the carrier fluid, in the "breakdown" and "build up" curve. This trend is identical for the estimated viscosity at a shear rate of zero.

Likewise, it is observed from the $m$ parameter a less pseudoplastic behavior for the "build-up" curves as their values are close to 0 , which is related to the fluid response to stress submission and its internal structure breakdown. Moreover, it is observed a higher relaxation time for the build-up curve corresponding to the EHO in the presence of the nanofluid, indicating that the time needed for the internal structure recovery of the system including the nanofluid is higher than for the system with the carrier fluid. The inclusion of the Carreau model for the interpretation of the experimental data, provides a more noticeable difference in the characteristic relaxation $\left(\lambda_{c}\right)$ parameter, as it is observed more clearly the increase in its value upon the treatments addition, and in particular, for the nanofluid, indicating a more time-dependent behavior for the nanofluid-EHO system. The Carreau model fitting to the experimental data can be observed in Figure S7 of the supplementary material.

From the estimated parameter of the Vipulanandan rheological model, it can be seen a good fitting of the model to the experimental data as the RSME\% is lower than $2 \%$ for both cases with a better fitting for the EHO-Carrier fluid system. Moreover, it can be seen a lower value of $\tau_{0}$ for the EHO-nanofluid system, indicating that a lower energy would be needed for initializing the fluid flow with the nanoparticles inclusion, result that is in accordance with that observed in previous studies in which the yield stress of an $\mathrm{EHO}$ is decreased in the presence of $\mathrm{SiO}_{2}$ nanoparticles [7]. Furthermore, the estimated values denote a higher maximum stress value reached by the $\mathrm{EHO}$ with the addition of nanofluids which is derived from the EHO internal structure rearrangement caused by the asphaltenes adsorption phenomenon that could be affecting other EHO rheological properties such as the elastic contributions, leading to a diminishing in the creep and fracture properties usually found in this type of viscoelastic fluids [65-67].

In Figure 9 is illustrated the EHO internal structure modification in a rheological profile which are mainly derived from the stress change as the shear rate increases, and also by the addition of the carrier fluid in panel (a) and the nanofluid in panel (b) to the system. From Figure 9, it can be seen the typical EHO viscosity reduction related to its internal structure breakdown upon a stress submission [68]. The increased strain caused by the stress generates a rearrange in the asphaltenes aggregates that compose the viscoelastic network [66], weakening the aggregates interactions and leading to a decrease in the elastic contributions to the fluid behavior and thus to a viscosity reduction [65].

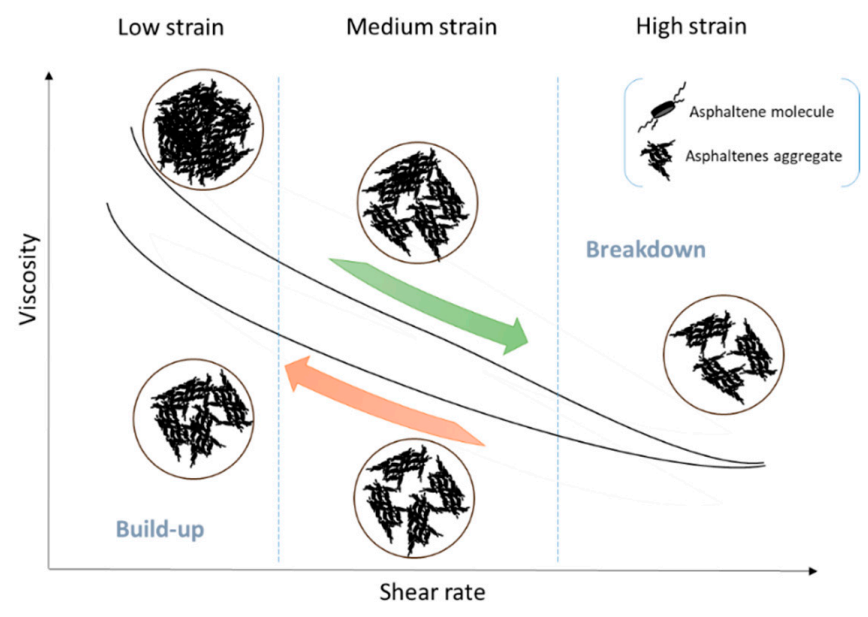

(a)

Figure 9. Cont. 


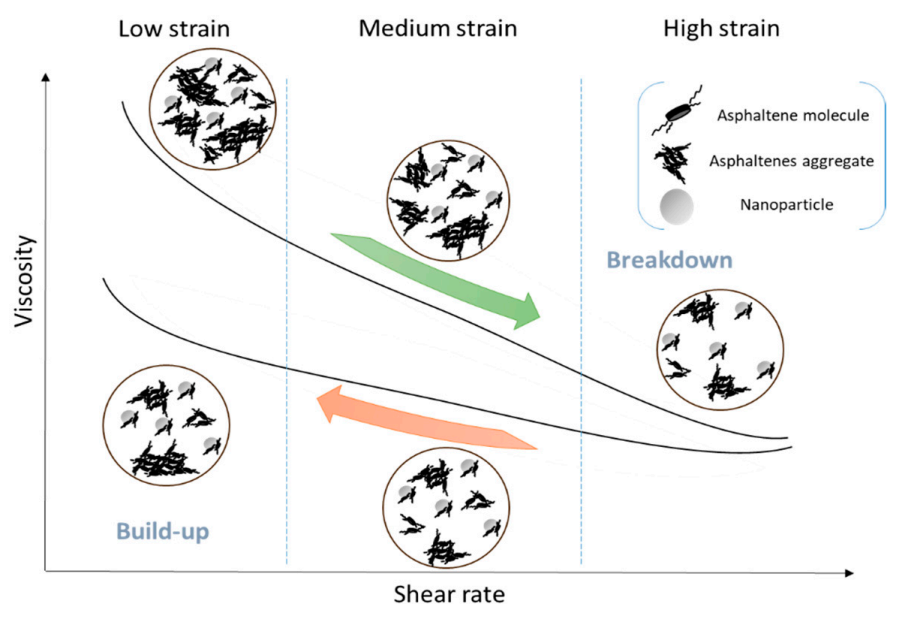

(b)

Figure 9. Hysteresis scheme representing the extra-heavy oil (EHO) internal structure modification with the shear rate increase and decrease for (a) the EHO-carrier fluid system and (b) the EHO-nanofluid system.

Moreover, with the nanoparticles addition to the $\mathrm{EHO}$, the asphaltenes aggregates sizes are considerably reduced [30], and the asphaltenes-asphaltenes interactions are limited [12,29]. As a consequence, the EHO viscoelastic network is disrupted, and its rheological properties are severely modified, making it behave more as a Newtonian fluid and reducing its viscosity in all the shear rate range [7].

The hysteresis phenomenon is also well schematized in Figure 9 where it is shown the build-up curve alongside the aforementioned breakdown curve. It can be seen from Figure 9 that the system with the addition of the carrier fluid has an internal structure capable of recovering its original arrangement in the same shear rate ramp. For the EHO-nanofluid system, the oil matrix rearrangement to its original state is slower as the nanoparticles may hinder the viscoelastic network reorganization through asphaltenes adsorption. Increasing the thixotropic effect of the EHO with the nanofluid reflects that the ability for structure build-up is slower than that of the EHO with the carrier fluid, indicating an increase in the durability of the nanofluid effect in the viscosity reduction. Hence, viscosity reduction measurements were performed for one month to verify the hypothesis.

\subsubsection{Evaluation of Viscosity Reduction Durability}

The viscosity perdurability was measured for 30 days at $30{ }^{\circ} \mathrm{C}$ in the presence of $5 \mathrm{vol} \%$ of the carrier fluid and the nanofluid as shown in Figure 10. The tests were carried out to prove if after the treatment application, the obtained viscosity reduction is maintained over time, as it was expected that with the addition of nanoparticles to the treatment and further asphaltenes adsorption, the breakage of the aggregates could be more durable. It can be observed from Figure 10 a viscosity increase for the treated EHO, being significantly higher for the EHO in the absence of nanoparticles, although there are visible negligible changes after 10 days (until the 30 days measured) as it can be seen no important alterations in the viscosity increment slope after this lapse. This behavior may be due to the evaporation of the xylene, which allows the system to recover its original viscosity partially up to $80 \%$ regarding the treatment-EHO baseline system. Nevertheless, due to the inclusion of nanoparticles in the treatment, better viscosity sustainability is obtained as the original viscosity reached after the treatment addition, just increased by $20 \%$. This last could be explained by the asphaltenes adsorption onto the nanoparticles surface upon nanofluid blending with the crude oil, phenomenon which disrupts the EHO viscoelastic network. This adsorption process has an irreversible nature [69], which avoids the asphaltenes to interact with each other after the xylene evaporation from the nanofluid-EHO system, while in the carrier fluid-EHO system, the xylene evaporation allows the asphaltenes aggregation in the fluid leading to partial EHO internal structure recovery. Hence, during 
the transporting operation of the crude oil, the energy requirements can be lowered with the nanofluid usage, which impacts the technical and economical availability of EHO projects [33].

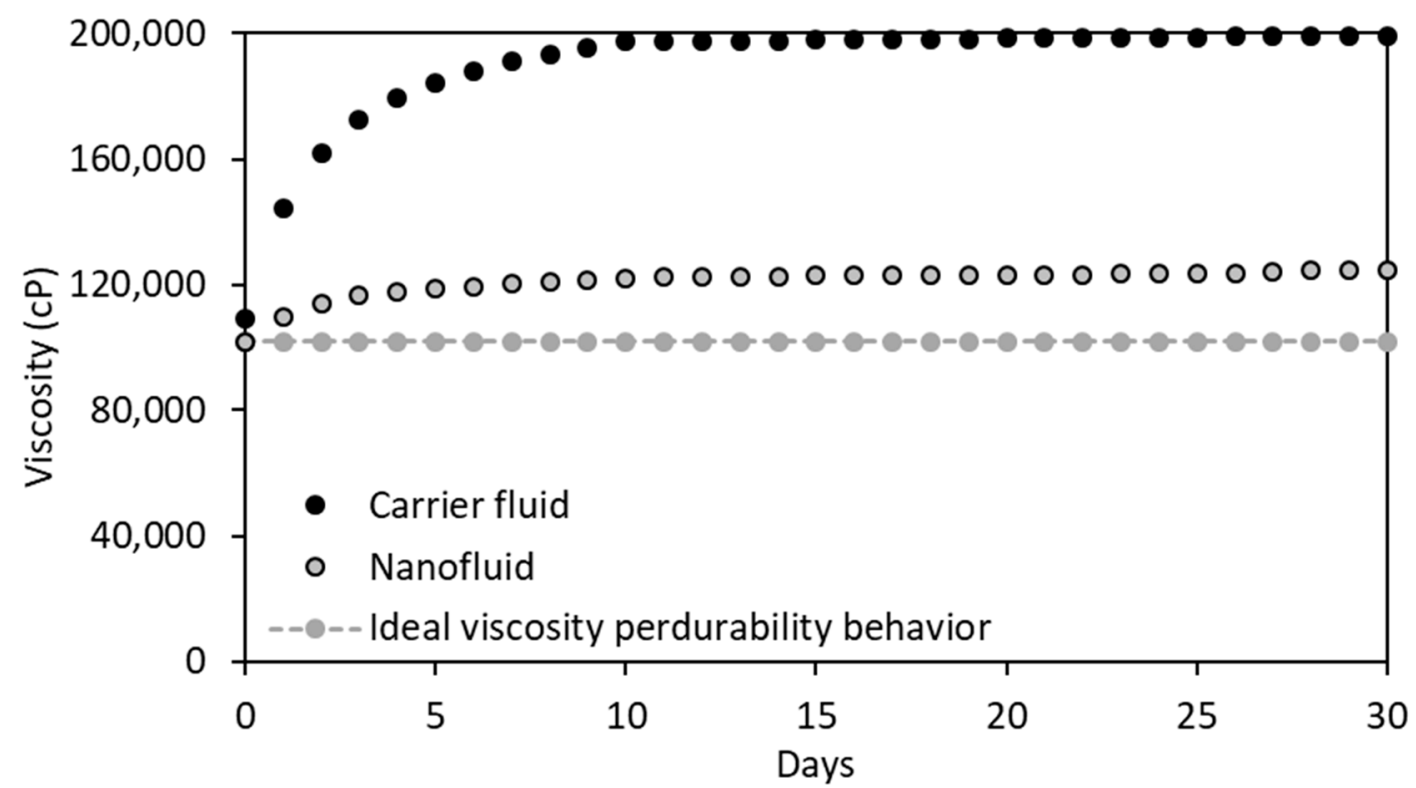

Figure 10. Viscosity perdurability behavior for the treated extra-heavy oil at $30{ }^{\circ} \mathrm{C}$ in the presence of $5 \mathrm{vol} \%$ of the carrier fluid composed of a xylene/dimethylformamide ratio of 0.2 and the nanofluid with $\mathrm{S} 9$ nanoparticles at $1000 \mathrm{mg} \cdot \mathrm{L}^{-1}$ suspended in the carrier fluid.

\section{Conclusions}

The nanofluid design for increasing the carrier-fluid-nanoparticles synergy starting from diluents viscosity reduction analysis showed a better performance for aromatics such as xylene $(X)$ because of its quality regarding asphaltenes stabilization in oil matrix instead of alkanes such as $n$-pentane, Diesel, and $n$-heptane. Moreover, DMF which was used as nanoparticles dispersant also showed a better performance in viscosity reduction than that observed for the diluents, which is explained by its interaction with asphaltenes due to its chemical structure. For the carrier fluid design, different X/DMF ratios were evaluated with the best performance for an $\mathrm{X} / \mathrm{DMF}=0.2$ in a dosage of a volume fraction of $5 \%$ regarding the highest VRD. Higher viscosity reduction performances were observed evaluating different $\mathrm{X} / \mathrm{DMF}$ ratios than using the diluent and dispersant separately. These results suggest a synergistic effect of the DMF and xylene in the disruption of the viscoelastic network. For dosages higher than 5\%, the DMF may have no significant effect on the viscoelastic network disruption as the VRD does not increase significantly.

By the evaluation of $\mathrm{SiO}_{2}$ nanoparticles in viscosity reduction, a trend between the viscosity reduction degree (VRD) and the nanoparticles surface area was obtained. The best results with solid nanoparticles were achieved using the S9 material with a VRD of 19\%, and these nanoparticles were selected for the final nanofluid design. When nanoparticles are included in the carrier fluid, a slight increase of $4 \%$ in the VRD was obtained. However, from the hysteresis loop evaluation for assessing the EHO thixotropy, it was determined that with the inclusion of nanoparticles to the carrier fluid-EHO system, the thixotropic behavior is increased, suggesting a better perdurability of the viscosity reduction. Hence, it is inferred that the internal structure of the crude oil would take more time for recovering its original form in comparison with the system in the absence of nanoparticles. This result is in agreement with the Cross and Carreau models that indicate an increase in the characteristic relaxation time values for the EHO-nanofluid systems, which is related to a more thixotropic behavior obtained for this sample. Also, from the Vipulanandan model, it was observed a decrease in the energy needed for initializing EHO transportation operations for the EHO-nanofluid 
system compared with the EHO-carrier fluid as the yield stress value is lower for the former. An increase in the maximum shear stress reached by the treatment including nanoparticles was estimated, which could be related to the fluid internal structure rearrangement that leads to a decrease in the elastic contributions of the EHO rheological behavior. Finally, the viscosity perdurability tests proved that in the carrier fluid-EHO system, the viscosity increased 80\% after 10 days, while for the EHO-nanofluid system the increase was $20 \%$. This effect is directly associated with the asphaltenes irreversible adsorption over nanoparticles surface and provides better insight into the effect of nanoparticles and nanofluids in the improvement of heavy and extra-heavy oils mobility.

It is expected with this study to remark the influence of an appropriate nanofluid design for enhancing their capacity for reducing EHO viscosity and seize their advantages in naphtha consumption reduction for transportation operations, decreasing operational costs.

Supplementary Materials: The following are available online at http:/ /www.mdpi.com/1996-1073/12/6/1068/ s1, Figure S1. Calibration curve obtained for the EHO asphaltenes in toluene solutions, Figure S2. FTIR analysis for S9, S11 and S66 nanoparticles, Figure S3. The visual appearance of (a) the carrier fluid and (b) the nanofluid, Figure S4. Rheological behavior evaluated for the EHO with a dosage of 5 vol \% of xylene with plate-plate and cone-plate geometries at $30{ }^{\circ} \mathrm{C}$, Figure S5. Asphaltenes adsorption isotherms performed for S9, S11 and S66 nanoparticles, Figure S6. Rheological behavior of an extra-heavy oil (EHO) in the absence and presence of $1000 \mathrm{mg} \cdot \mathrm{L}^{-1}$ of $\mathrm{SiO}_{2}$ nanoparticles with different mean particle sizes of 9 (S9), 11 (S11), and $66 \mathrm{~nm}$ (S66) at $30{ }^{\circ} \mathrm{C}$. The symbols are experimental data, and the continuous lines are from the Carreau model, Figure S7. Hysteresis behavior at $30{ }^{\circ} \mathrm{C}$ for an extra-heavy oil in the presence of $5 \mathrm{vol} \%$ of a) the carrier fluid composed of a xylene/dimethylformamide ratio of 0.2 , and b) the nanofluid with $\mathrm{S} 9$ nanoparticles at $1000 \mathrm{mg} \cdot \mathrm{L}^{-1}$ composed by the carrier fluid. The symbols are experimental data, and the continuous lines are from the Carreau model, Table S1. SLE parameters for the obtained adsorption isotherms.

Author Contributions: The authors state their following contribution to this study development: conceptualization, D.M., E.A.T., C.A.F. and F.B.C.; methodology, D.M., E.A.T., C.A.F. and F.B.C.; validation, D.M., E.A.T., C.A.F. and F.B.C.; formal analysis, D.M. and E.A.T. investigation, D.M.; resources, W.O.; writing-original draft preparation, D.M.; writing-review and editing, D.M., E.A.T., C.A.F. and F.B.C.; visualization, D.M.; supervision, C.A.F. and F.B.C.; project administration, C.A.F. and W.O.; funding acquisition, W.O.

Funding: The authors would like to acknowledge COLCIENCIAS and Agencia Nacional de Hidrocarburos (ANH-Colombia) for their support provided in Agreement 272-2017.

Acknowledgments: Authors acknowledge the Universidad Nacional de Colombia for logistical support.

Conflicts of Interest: The authors declare no conflict of interest.

\section{References}

1. Owen, N.A.; Inderwildi, O.R.; King, D.A. The status of conventional world oil reserves-Hype or cause for concern? Energy Policy 2010, 38, 4743-4749. [CrossRef]

2. Alboudwarej, H.; Felix, J.; Taylor, S.; Badry, R.; Bremner, C.; Brough, B.; Skeates, C.; Baker, A.; Palmer, D.; Pattison, K. La importancia del petróleo pesado. Oilfield Rev. 2006, 18, 38-59.

3. Youngquist, W. The post-petroleum paradigm-And population. Popul. Environ. 1999, 20, $297-315$. [CrossRef]

4. Luo, P.; Gu, Y. Effects of asphaltene content and solvent concentration on heavy oil viscosity. In Proceedings of the SPE International Thermal Operations and Heavy Oil Symposium, Calgary, AB, Canada, 1-3 November 2005.

5. Kröcher, O.; Köppel, R.A.; Fröba, M.; Baiker, A. Silica Hybrid Gel Catalysts Containing Group (VIII) Transition Metal Complexes: Preparation, Structural, and Catalytic Properties in the Synthesis of N,N-Dimethylformamide and Methyl Formate from Supercritical Carbon Dioxide. J. Catal. 1998, 178, 284-298. [CrossRef]

6. Pierre, C.; Barré, L.; Pina, A.; Moan, M. Composition and heavy oil rheology. Oil Gas Sci. Technol. 2004, 59, 489-501. [CrossRef]

7. Taborda, E.A.; Alvarado, V.; Franco, C.A.; Cortés, F.B. Rheological demonstration of alteration in the heavy crude oil fluid structure upon addition of nanoparticles. Fuel 2017, 189, 322-333. [CrossRef]

8. Yen, T.; Chilingarian, G. Asphaltenes and asphalts, Develop-ments in Petroleum Science; Elsevier Science BV: Amsterdam, The Netherlands, 1994.

9. Mullins, O.C. The asphaltenes. Annu. Rev. Anal. Chem. 2011, 4, 393-418. [CrossRef] [PubMed] 
10. Mullins, O.C.; Andrews, B.; Pomerantz, A.; Dong, C.; Zuo, J.Y.; Pfeiffer, T.; Latifzai, A.S.; Elshahawi, H.; Barre, L.E.; Larter, S. Impact of Asphaltene nanoscience on understanding oilfield reservoirs. In Proceedings of the SPE Annual Technical Conference and Exhibition, Denver, CO, USA, 30 October-2 November 2011.

11. Mullins, O.C.; Sabbah, H.; Eyssautier, J.; Pomerantz, A.E.; Barré, L.; Andrews, A.B.; Ruiz-Morales, Y.; Mostowfi, F.; McFarlane, R.; Goual, L. Advances in asphaltene science and the Yen-Mullins model. Energy Fuels 2012, 26, 3986-4003. [CrossRef]

12. Franco, C.A.; Lozano, M.M.; Acevedo, S.; Nassar, N.N.; Cortés, F.B. Effects of resin I on asphaltene adsorption onto nanoparticles: A novel method for obtaining asphaltenes/resin isotherms. Energy Fuels 2015, 30, 264-272. [CrossRef]

13. Urquhart, R. Heavy oil transportation-present and future. J. Can. Pet. Technol. 1986, 25. [CrossRef]

14. Nuñez, G.; Guevara, E.; Gonzalez, J. Highly viscous oil transportation methods in the Venezuela industry. In Proceedings of the 15th World Petroleum Congress, Beijing, China, 12-17 October 1997; pp. 495-502.

15. Yaghi, B.M.; Al-Bemani, A. Heavy crude oil viscosity reduction for pipeline transportation. Energy Sources 2002, 24, 93-102. [CrossRef]

16. Hart, A. A review of technologies for transporting heavy crude oil and bitumen via pipelines. J. Pet. Explor. Prod. Technol. 2014, 4, 327-336. [CrossRef]

17. Martínez-Palou, R.; de Lourdes Mosqueira, M.; Zapata-Rendón, B.; Mar-Juárez, E.; Bernal-Huicochea, C.; de la Cruz Clavel-López, J.; Aburto, J. Transportation of heavy and extra-heavy crude oil by pipeline: A review. J. Pet. Sci. Eng. 2011, 75, 274-282. [CrossRef]

18. Escojido, D.; Urribarri, O.; Gonzalez, J. Part 1: Transportation of Heavy Crude Oil and Natural Bitumen. In Proceedings of the 13th World Petroleum Congress, Buenos Aires, Argentina, 20-25 October 1991; pp. 15-22.

19. Saniere, A.; Hénaut, I.; Argillier, J. Pipeline transportation of heavy oils, a strategic, economic and technological challenge. Oil Gas Sci. Technol. 2004, 59, 455-466. [CrossRef]

20. Argillier, J.; Barre, L.; Brucy, F.; Dournaux, J.; Henaut, I.; Bouchard, R. Influence of asphaltenes content and dilution on heavy oil rheology. In Proceedings of the SPE International Thermal Operations and Heavy Oil Symposium, Porlamar, Venezuela, 12-14 March 2001.

21. Argillier, J.; Henaut, I.; Heraud, J.-P.; Glenat, P. Heavy oil dilution. In Proceedings of the SPE International Thermal Operations and Heavy Oil Symposium, Calgary, AB, Canada, 1-3 November 2005.

22. Gateau, P.; Hénaut, I.; Barré, L.; Argillier, J. Heavy oil dilution. Oil Gas Sci. Technol. 2004, 59, 503-509. [CrossRef]

23. Jamaluddin, A.; Nazarko, T.; Sills, S.; Fuhr, B. Deasphalted Oil-A Natural Asphaltene Solvent. SPE Prod. Facil. 1996, 11, 161-165. [CrossRef]

24. Franco, C.A.; Zabala, R.; Cortés, F.B. Nanotechnology applied to the enhancement of oil and gas productivity and recovery of Colombian fields. J. Pet. Sci. Eng. 2017, 157, 39-55. [CrossRef]

25. Zabala, R.; Franco, C.; Cortés, F. Application of Nanofluids for Improving Oil Mobility in Heavy Oil and Extra-Heavy Oil: A Field Test. In Proceedings of the SPE Improved Oil Recovery Conference, Tulsa, OK, USA, 11-13 April 2016.

26. Zabala, R.; Mora, E.; Botero, O.; Cespedes, C.; Guarin, L.; Franco, C.; Cortes, F.; Patino, J.; Ospina, N. Nano-technology for asphaltenes inhibition in Cupiagua South Wells. In Proceedings of the IPTC 2014: International Petroleum Technology Conference, Kuala Lumpur, Malaysia, 10-12 December 2014.

27. Guzmán, J.D.; Betancur, S.; Carrasco-Marín, F.; Franco, C.A.; Nassar, N.N.; Cortés, F.B. Importance of the adsorption method used for obtaining the nanoparticle dosage for asphaltene-related treatments. Energy Fuels 2016, 30, 2052-2059. [CrossRef]

28. Betancur, S.; Carmona, J.C.; Nassar, N.N.; Franco, C.A.; Cortés, F.B. Role of particle size and surface acidity of silica gel nanoparticles in inhibition of formation damage by asphaltene in oil reservoirs. Ind. Eng. Chem. Res. 2016, 55, 6122-6132. [CrossRef]

29. Franco, C.A.; Nassar, N.N.; Ruiz, M.A.; Pereira-Almao, P.; Cortés, F.B. Nanoparticles for inhibition of asphaltenes damage: Adsorption study and displacement test on porous media. Energy Fuels 2013, 27, 2899-2907. [CrossRef]

30. Taborda, E.A.; Franco, C.A.; Lopera, S.H.; Alvarado, V.; Cortés, F.B. Effect of nanoparticles/nanofluids on the rheology of heavy crude oil and its mobility on porous media at reservoir conditions. Fuel 2016, 184, 222-232. [CrossRef] 
31. Alomair, O.A.; Matar, K.M.; Alsaeed, Y.H. Nanofluids application for heavy oil recovery. In Proceedings of the SPE Asia Pacific Oil \& Gas Conference and Exhibition, Adelaide, Australia, 14-16 October 2014.

32. Aristizábal-Fontal, J.E.; Cortés, F.B.; Franco, C.A. Viscosity reduction of extra heavy crude oil by magnetite nanoparticle-based ferrofluids. Adsorpt. Sci. Technol. 2017, 36, 23-45. [CrossRef]

33. Taborda, E.A.; Alvarado, V.; Cortés, F.B. Effect of $\mathrm{SiO}_{2}$-based nanofluids in the reduction of naphtha consumption for heavy and extra-heavy oils transport: Economic impacts on the Colombian market. Energy Convers. Manag. 2017, 148, 30-42. [CrossRef]

34. Taborda, E.A.; Franco, C.A.; Ruiz, M.A.; Alvarado, V.; Cortés, F.B. Experimental and theoretical study of viscosity reduction in heavy crude oils by addition of nanoparticles. Energy Fuels 2017, 31, 1329-1338. [CrossRef]

35. Stöber, W.; Fink, A.; Bohn, E. Controlled growth of monodisperse silica spheres in the micron size range. J. Colloid Interface Sci. 1968, 26, 62-69. [CrossRef]

36. Hench, L.L.; West, J.K. The sol-gel process. Chem. Rev. 1990, 90, 33-72. [CrossRef]

37. Franco, C.A.; Montoya, T.; Nassar, N.N.; Pereira-Almao, P.; Cortés, F.B. Adsorption and subsequent oxidation of colombian asphaltenes onto nickel and/or palladium oxide supported on fumed silica nanoparticles. Energy Fuels 2013, 27, 7336-7347. [CrossRef]

38. Brauneur, S.; Emmet, P.; Teller, E. Adsorption of gases in multi molecular layer. J. Am. Chem. Soc 1938, 60, 309-319. [CrossRef]

39. Leofanti, G.; Padovan, M.; Tozzola, G.; Venturelli, B. Surface area and pore texture of catalysts. Catal. Today 1998, 41, 207-219. [CrossRef]

40. Socrates, G. Infrared and Raman Characteristic Group Frequencies: Tables and Charts; John Wiley \& Sons: Hoboken, NJ, USA, 2004.

41. Yao, H.; Dai, Q.; You, Z. Fourier Transform Infrared Spectroscopy characterization of aging-related properties of original and nano-modified asphalt binders. Constr. Build. Mater. 2015, 101, 1078-1087. [CrossRef]

42. Asomaning, S. Test methods for determining asphaltene stability in crude oils. Pet. Sci. Technol. 2003, 21, 581-590. [CrossRef]

43. Gafanhao, M.; Sánchez, E.J.I.; Linares, J.G.D. Determinación del punto de precipitación de los asfaltenos en crudos venezolanos. Ciencia e Ingeniería 2008, 29, 225-232.

44. Salager, J.; Fernández, A. Módulo de enseñanza en fenómenos interfaciales. Venezuela: Universidad de los Andes y Ministerio de Ciencia y Tecnología. Available online: http:/ /www.firp.ula.ve/site/es/cuadernosfirpgratuitos (accessed on 17 March 2019).

45. Montoya, T.; Coral, D.; Franco, C.A.; Nassar, N.N.; Cortés, F.B. A novel solid-liquid equilibrium model for describing the adsorption of associating asphaltene molecules onto solid surfaces based on the "Chemical Theory". Energy Fuels 2014, 28, 4963-4975. [CrossRef]

46. Chalaris, M.; Samios, J. Systematic molecular dynamics studies of liquid $N, N$-dimethylformamide using optimized rigid force fields: Investigation of the thermodynamic, structural, transport and dynamic properties. J. Chem. Phys. 2000, 112, 8581-8594. [CrossRef]

47. Páez, M.; Vergara, M.; Cantero, P. Propiedades volumétricas de la mezcla $N, N$-dimetilformamida+ 1-propanol a diferentes temperaturas. Revista Colombiana de Química 2012, 41, 75-88.

48. Sarpkaya, T. Flow of non-Newtonian fluids in a magnetic field. AIChE J. 1961, 7, 324-328. [CrossRef]

49. Shao, S.; Lo, E.Y. Incompressible SPH method for simulating Newtonian and non-Newtonian flows with a free surface. Adv. Water Resour. 2003, 26, 787-800. [CrossRef]

50. Nik, W.W.; Ani, F.; Masjuki, H.; Giap, S.E. Rheology of bio-edible oils according to several rheological models and its potential as hydraulic fluid. Ind. Crop. Prod. 2005, 22, 249-255. [CrossRef]

51. Vipulanandan, C.; Mohammed, A. Hyperbolic rheological model with shear stress limit for acrylamide polymer modified bentonite drilling muds. J. Pet. Sci. Eng. 2014, 122, 38-47. [CrossRef]

52. Vipulanandan, C.; Mohammed, A. Smart cement rheological and piezoresistive behavior for oil well applications. J. Pet. Sci. Eng. 2015, 135, 50-58. [CrossRef]

53. Vipulanandan, C.; Mohammed, A. Effect of nanoclay on the electrical resistivity and rheological properties of smart and sensing bentonite drilling muds. J. Pet. Sci. Eng. 2015, 130, 86-95. [CrossRef]

54. Vipulanandan, C.; Mohammed, A.; Qu, Q. Characterizing the hydraulic fracturing fluid modified with nano silica proppant. In Proceedings of the AADE Fluids Technical Conference and Exhibition, Houston, TX, USA, 12-13 April 2016; pp. 15-16. 
55. Hunter, R.J. Zeta Potential in Colloid Science: Principles and Applications; Academic Press: Cambridge, MA, USA, 2013; Volume 2.

56. Minale, M.; Merola, M.C.; Carotenuto, C. Effect of solvents on the microstructure aggregation of a heavy crude oil. Fuel Process. Technol. 2018, 177, 299-308. [CrossRef]

57. Taborda, E.A.; Franco, C.A.; Ruiz, M.A.; Alvarado, V.; Cortés, F.B. Anomalous Heavy-Oil Rheological Thinning Behavior upon Addition of Nanoparticles: Departure from Einstein's Theory. Chem. Eng. Commun. 2017, 204, 648-657. [CrossRef]

58. Thommes, M.; Kaneko, K.; Neimark, A.V.; Olivier, J.P.; Rodriguez-Reinoso, F.; Rouquerol, J.; Sing, K.S. Physisorption of gases, with special reference to the evaluation of surface area and pore size distribution (IUPAC Technical Report). Pure Appl. Chem. 2015, 87, 1051-1069. [CrossRef]

59. Livescu, S. Mathematical modeling of thixotropic drilling mud and crude oil flow in wells and pipelinesA review. J. Pet. Sci. Eng. 2012, 98, 174-184. [CrossRef]

60. Mortazavi-Manesh, S.; Shaw, J.M. Thixotropic rheological behavior of Maya crude oil. Energy Fuels 2014, 28, 972-979. [CrossRef]

61. Cheng, D.C.; Evans, F. Phenomenological characterization of the rheological behaviour of inelastic reversible thixotropic and antithixotropic fluids. Br. J. Appl. Phys. 1965, 16, 1599. [CrossRef]

62. Hahn, S.J.; Ree, T.; Eyring, H. Flow mechanism of thixotropic substances. Ind. Eng. Chem. 1959, 51, 856-857. [CrossRef]

63. Moore, F. The rheology of ceramic slip and bodies. Trans. Br. Ceram. Soc. 1959, 58, 470-492.

64. Peter, S. Zur Theorie der Rheopexie. Rheol. Acta 1964, 3, 178-180. [CrossRef]

65. Behzadfar, E.; Hatzikiriakos, S.G. Viscoelastic properties and constitutive modelling of bitumen. Fuel 2013, 108, 391-399. [CrossRef]

66. Visintin, R.F.; Lapasin, R.; Vignati, E.; D'Antona, P.; Lockhart, T.P. Rheological behavior and structural interpretation of waxy crude oil gels. Langmuir 2005, 21, 6240-6249. [CrossRef]

67. Wardhaugh, L.; Boger, D. The measurement and description of the yielding behavior of waxy crude oil. J. Rheol. 1991, 35, 1121-1156. [CrossRef]

68. Ghannam, M.T.; Hasan, S.W.; Abu-Jdayil, B.; Esmail, N. Rheological properties of heavy \& light crude oil mixtures for improving flowability. J. Pet. Sci. Eng. 2012, 81, 122-128.

69. Cortés, F.B.; Montoya, T.; Acevedo, S.; Nassar, N.N.; Franco, C.A. Adsorption-desorption of n-c7 asphaltenes over micro- and nanoparticles of silica and its impact on wettability alteration. CTEF-Ciencia, Tecnología y Futuro 2016, 6, 89-106. 